\title{
Estudio comparativo del capitalismo argentino $y$ chileno: un análisis desde las redes de directorio a fines del modelo sustitutivo de importaciones ${ }^{1}$
}

\author{
Erica Salvaj²- Universidad del Desarrollo, Chile. \\ Andrea Lluch ${ }^{3}$ - CONICET, Argentina
}

\section{Resumen}

La investigación sobre redes de directorios se ha llevado a cabo principalmente en los Estados Unidos y los países europeos. Escasos son los trabajos de investigación, ya sea de la naturaleza teórica o empírica, que han estudiado las características y los factores que afectan a esta importante red inter empresarial en economías periféricas y turbulentas. En este estudio comparativo e histórico, nos centramos en el efecto de la turbulencia política y económica y la composición de la propiedad de las empresas más importantes en la configuración de la estructura de las redes de directorios en Argentina y Chile a finales de los años sesenta. Las principales conclusiones de este análisis son las siguientes: 1) las redes de directorio son mas fragmentadas en Argentina que en Chile, 2) la mayoría de los actores mas relevantes en la red argentina son empresas de sectores considerados estratégicos por el gobierno, 3) las filiales de multinacionales ocupan una posición central en Argentina, y 4) los bancos y las empresas de propiedad de grupos de negocios locales jugaron un papel central en la red de directorios chilena. Este estudio muestra cómo los factores institucionales y económicos afectan la estructura de relaciones entre empresas.

Palabras clave: Turbulencia política y económica, redes de directorios, empresas de Argentina y Chile

\begin{abstract}
Research on interlocking directorates has been conducted primarily in the United States and European countries. Little work of either theoretical or empirical nature has been done to study the characteristics and the factors that affect this important business network in peripheral and turbulent economies. In this comparative and historical study, we focus on the effect of the political and economic turbulence and the ownership composition of the largest firms on shaping the structure of interlocking directorates in Argentina and Chile by the end of the sixties. Four main findings result from this analysis: 1) the interlocking directorate in Argentina is more fragmented than in Chile; 2 ) most relevant actors in the directorship interlock in Argentina are firms in industries considered strategic by the government; 3 ) multinational subsidiaries occupy a central position in Argentina; 4) banks and firms owned by local business groups played a central role in the interlocking directorates in Chile. This study shows how the institutional and economic factors shape the structure of relations between companies.
\end{abstract}

Keywords: Political and economic turbulence, interlocking directorates, Companies from Argentina and Chile

\footnotetext{
${ }^{1}$ Los datos de este trabajo provienen del proyecto de investigación financiado por el Gobierno de Chile, Fondecyt 11085048, titulado "Dynamics in the Chilean System of Corporate Governance. An Empiricial Study on the evolution of corporate networks in Chile from 1968 to 2006".

${ }^{2}$ E-mail: esalvaj@udd.cl

${ }^{3}$ E-mail: alluch@conicet.gov.ar
} 


\section{Introducción}

Las redes de directorios surgieron a fines del siglo XIX como medio de coordinación y organización de las actividades empresariales de las sociedades anónimas. Desde entonces, las redes de directorios (RD) - creadas cuando dos empresas comparten un director común - han sido intensamente estudiadas por académicos y planificadores de políticas públicas. (Mizruchi, 1996; Hambrick, Werder y Zajac, 2008).

Las RD proveen capital social a las empresas (Windolf, 2008; Haynes y Hillman, 2010) y su funcionamiento ha sido vinculado con distintos resultados organizacionales. La literatura ha propuesto como una de sus posibles funciones la transferencia de información y la disminución del comportamiento oportunista (Mizruchi, 1996). Para otros autores generan diferenciación entre los directorios (Podolny, 2001), al afectar la legitimidad y reputación de las empresas (Davis y Robbins, 2004; Kang, 2008; Rhee y Valdez, 2009; Bucheli y Salvaj, 2012). Algunos estudios han vinculado la existencia de RD con la performance de las empresas. Por ejemplo, Silva, Majluf y Paredes (2006) han demostrado que las redes familiares y de directorio tienen un impacto positivo en los resultados de las empresas chilenas cuando la concentración de las acciones con derecho a voto es baja y los derechos a voto de los accionistas controladores convergen con sus derechos económicos.

Las RD también han sido utilizadas como mecanismos de control entre empresas (Pfeffer \& Salancik, 1978). Por ejemplo, los grupos económicos en Chile y Argentina utilizan intensamente las RD para controlar y facilitar el flujo de información entre sus compañías (Khana y Rivkin, 2006; Lluch, Salvaj y Barbero, 2011). Finalmente, estas redes pueden ser un mecanismo de vinculación con el sector público (Lester, Hillman, Zardkoohi y Canella, 2008). En Chile, las subsidiarias de multinacionales españolas tienden a utilizar más a menudo que otro tipo de empresas, directores con vinculaciones cercanas al gobierno (Bucheli y Salvaj, 2009).

En tal sentido, el estudio de este tipo de vínculos es muy útil para comprender cómo se configuran las relaciones inter organizacionales entre las empresas y cómo se organiza la economía de un país. En las últimas décadas, los investigadores han utilizado métodos sofisticados de análisis para examinar el capital social del directorio y la estructura de las redes de directorio en diversos países (Stokman, Ziegler y Scott, 1985; Windolf, 2002; Corrado y Zollo, 2006). Sin embargo, la mayoría de los estudios teóricos y empíricos sobre la estructura de la red corporativa se han llevado a cabo en países con entornos institucionales estables 
(Estados Unidos y Europa) y se basan principalmente en empresas que cotizan en la bolsa de valores (Windolf, 2002; Davis, Yoo y Baker, 2003; Salvaj y Ferraro 2005; Corrado y Zollo, 2006).

Debido a la pluralidad de modalidades en que el fenómeno de las redes de directorios se ha manifestado histórica y geográficamente, es prioritario analizar las redes de directorios en contextos diversos y no explorados por estudios previos. Nuestra investigación intenta cubrir este vacío, al abordar los casos de Argentina y Chile y postula que dos países con un tipo de capitalismo similar pueden tener estructuras de redes de directorios muy distintas (Granovetter, 1993; Rinaldi y Vasta, 2005).

En función del análisis de una base de datos de directorios de 165 empresas chilenas y 116 empresas argentinas, consideramos que las especificidades del entorno institucional y de las estructuras de propiedad de las firmas más grandes de cada país explican la estructura diferencial de sus redes corporativas a finales de la década de 1960. Nuestro estudio puntualiza cuatro hallazgos principales: 1) las redes de directorio estaban más fragmentadas en Argentina que en Chile; 2) los actores más importantes en la red de directorio argentina eran empresas de sectores industriales considerados estratégicos por el gobierno; 3) las subsidiarias de las empresas multinacionales ocupaban una posición más central en la Argentina que en Chile; 4) los bancos y las empresas propiedad de grupos económicos locales adquirieron un rol más central en las redes de directorios de Chile.

Este artículo se ha organizado de la siguiente manera: en la primera sección describimos los sistemas de directorio de Argentina y Chile y el concepto de redes corporativas. En la segunda sección explicamos las diferencias en el entorno institucional y económico y en la estructura de propiedad de las empresas de mayores ventas de Chile y Argentina y su influencia en las estructuras de las redes de directorios. El tercer apartado analiza el rol de los distintos tipos de empresas en las redes de directorios a partir de la aplicación de distintos indicadores provenientes del Social Network Analysis. La sección final sintetiza nuestros hallazgos y conclusiones.

\section{EI Directorio y las redes de directorio}

Una de las instituciones más importantes del sistema nacional de gobierno corporativo es el directorio. A fines de la década del 60, Chile tenía un sistema de directorio simple. En Argentina las empresas podían dividir las competencias entre el directorio y un comité de ejecución o directivo (formado por algunos directores). No obstante, la no obligatoriedad de esta práctica hacía que pocas empresas aplicaran este sistema, dificultando el encasillamiento de Argentina en el sistema 
latino (Stokman et al 1986). ${ }^{4}$ La sanción de la ley 19.550 (1972) estipuló la posibilidad de conformar un Consejo de vigilancia, pero aun así este órgano era (y es) de carácter optativo. En Argentina la fiscalización de las sociedades anónimas estaba a cargo de la figura del síndico. La sindicatura de empresas fue (hasta la reforma del Código de Comercio) un órgano permanente e indispensable de las sociedades anónimas, desempeñado por un funcionario elegido por los accionistas en Asamblea, con atribuciones legales mínimas inderogables e indelegables para la fiscalización de la administración de la sociedad.

Los miembros del directorio eran seleccionados en la reunión de accionistas. A los directores se les confiaba la administración inmediata de los negocios de la empresa. Las leyes argentina y chilena de ese momento no requerían un número específico de miembros en el directorio. Las funciones del directorio incluían la conducción de los negocios, la administración de los bienes y el gobierno del personal. El directorio era responsable además -solidaria e ilimitadamente- por las faltas de su gestión y la violación de las leyes, de los estatutos y de las decisiones de la asamblea.

Una práctica habitual de las empresas era invitar a sus directorios a miembros reputados del mundo empresarial o ejecutivos de confianza, quienes podían ocupar la posición de director en más de una empresa. Estos directores que participan simultáneamente en más de un directorio generan las redes de directorio (Mizruchi, 1996). Como indicamos previamente, una amplia literatura ha analizado las redes de directorio desde un punto de vista histórico y la han definido como "una institución importante del capitalismo organizado" la cual no reemplazó al mercado pero desempeñó funciones importantes - y cambiantes - en las economías capitalistas desde finales del siglo diecinueve. Windolf (2008) propone que la aparición de las grandes empresas que cotizaban en la bolsa (públicas en la literatura anglosajona) destruyó en cierta medida la base organizativa del mundo empresarial hasta entonces dominada por redes y empresas familiares. La red empresarial -emancipada parcialmente de relaciones de familia o propiedad- surgió como una nueva institución para coordinar las transacciones. Al mismo tiempo, a finales del siglo XIX, y según Windolf (2008), Useem (1984) y Koenig, Gogel, y Sonquist (1979), este tipo de redes se profesionalizaron y fueron reglamentadas por marcos jurídicos. Sin embargo, este proceso de transformaciones generalmente asociado al advenimiento del denominado capitalismo gerencial en los Estados Unidos y en algunos países europeos- no fue uniforme y por lo tanto es relevante entender cómo se organizaban las redes de directorios en contextos

\footnotetext{
${ }^{4}$ El denominado "Latin system" se distinguia por tener: "two-board systems, involving a distinction between an auditing board and an administrative board".
} 
caracterizados por un mayor peso del capitalismo familiar, una mayor turbulencia económica e institucional, un menor desarrollo del mercado de capitales y una más tardía profesionalización del mundo corporativo. ${ }^{5}$

\section{Entorno institucional y estructura organizativa de las empresas}

\section{Turbulencia del entorno: contexto político y económico}

La teoría de la "dependencia de los recursos" propone que la turbulencia del entorno afecta la utilidad y por tanto los usos potenciales de las redes de los directorios (Carpenter and Westphal, 2001; Shropshire, 2010). Por turbulencia del entorno nos referimos al nivel de complejidad e incertidumbre externa a la que se enfrenta una empresa (Boyd, 1990). Algunos aspectos específicos que delimitan a la denominada turbulencia del entorno incluyen la volatilidad económica y política, la falta de cohesión de la comunidad empresarial, las luchas entre grupos corporativos con intereses económicos diferentes, la intervención de las fuerzas armadas y la polarización política e ideológica.

En el período bajo estudio el grado de turbulencia del entorno económico e institucional de Argentina y Chile adquirió matices diferenciales en ambos casos. En el plano de las similitudes, ambos países, y debido al severo impacto de la Gran Depresión, habían mudado hacia estrategias de desarrollo vinculadas con políticas de industrialización por sustitución de importaciones (ISI) (Ardanaz, Scartascini y Tommasi, 2010). El modelo ISI se basaba en dos pilares fundamentales: una economía cerrada (altas barreras tarifarias, cupos y controles del tipo de cambio) y un fuerte rol del estado (el gasto público como gran parte del PBI, reglamentaciones extensivas y creciente presencia de empresas estatales) (Sapelli, 2003). La dinámica del crecimiento económico fue desigual en ambos países. Durante la segunda mitad del siglo XX, el rendimiento económico de Argentina se deterioró y desde entonces surgió un patrón de crecimiento volátil: un impulso inicial de crecimiento siempre era interrumpido por una crisis que provocaba una caída en el PBI, seguida de una lenta recuperación, para volver años más tarde a los niveles anteriores. Chile, por el contrario experimentó un crecimiento bajo pero relativamente estable desde mediados de la década de 1930 hasta comienzos de los 70 (Fourcade-Gourinchas y Babb, 2002).

\footnotetext{
5 Son escasas las investigaciones que abordan históricamente el proceso de profesionalización del management en ambos países. Sin embargo, la importancia de la propiedad familiar en el capitalismo de ambos países ha sido considerado una variable fundamental para explicar una posible menor profesionalización del staff generecial. Sin embargo, este tema deberá ser profundizado en estudios posteriores.
} 
En el caso de Argentina, las políticas ISI Ilevaron a un rápido desarrollo del sector industrial, pero las exportaciones no crecieron significativamente, y con el tiempo esto fue el núcleo del estancamiento económico que marcó el eventual colapso del modelo. Este período evidenció una notable continuidad en la aplicación de las políticas generales asociadas con una estrategia ISI. Sin embargo, la ISI más profunda se implementó después de 1958, dirigida a los sectores de provisión de insumos y bienes de capital y a la promoción de las exportaciones industriales. Durante 1958-1962, el programa económico del denominado desarrollismo recuperó la idea de una aceleración del crecimiento a través de un estímulo a las inversiones, concentrándolas en unos pocos sectores de capital intensivo y sustitutivos de las importaciones (Barbero y Rocchi, 2003). Posteriormente, durante el régimen militar de Onganía (1966-1970), también se promovió la industrialización. En primer lugar, se distorsionó la relación entre los precios internos y externos para proteger al sector industrial. Segundo, se creó un complejo sistema de incentivos a la inversión a los efectos de proteger la industria y se implementó un régimen de "compre nacional" (Acuña, Galiani y Tommasi, 2006). Tercero, también se promovió la industrialización por medio de la inversión directa de parte del gobierno en industrias consideradas estratégicas: hierro y acero, petroquímica y papel y pulpa. Finalmente, el gobierno extendió las facilidades financieras a través de los créditos de BIRA/BANADE (bancos de propiedad estatal).

La política económica chilena estuvo caracterizada también por la aplicación de estrategias ISI, aun cuando el gobierno de Alessandri (1958-1964) -líder del partido conservador y empresario- realizó algunos intentos de liberalización. Dichos pasos contribuyeron a estabilizar la inflación y a promover el crecimiento económico al tiempo que alejaban al país de una estrategia de desarrollo industrial que miraba hacia adentro. Sin embargo, muchas de estas políticas de liberalización tuvieron corta vida. El crecimiento de las importaciones y el incremento del gasto en obras públicas y programas habitacionales provocaron un desequilibrio comercial y una moneda sobrevaluada. Desde 1962, la crisis en la balanza de pagos llevó a la devaluación del peso y a la restauración del proteccionismo comercial (Kline, 1992).

Durante la presidencia de Frei Montalva, se promovió una economía mixta, donde el gobierno adquirió un rol más activo. Frei Montalva fomentó la llamada "Revolución en libertad", la cual marcó el comienzo de un proceso de expropiación de las minas de cobre y de reforma agraria. Este programa preveía obtener la participación del gobierno (eventualmente un 51 por ciento) en la propiedad de las grandes minas de cobre de Chile, junto con compromisos para aumentar la producción. En ese 
momento, dos tercios de los ingresos por exportaciones de Chile provenían de esta industria, pero la mayoría de las minas eran propiedad de empresas estadounidenses (Kline, 1992). A pesar de los planes de reforma de Frei, hacia finales de los años 60, la economía chilena no había mejorado, y, entre 1950 y 1970, su rendimiento económico fue el más pobre entre los países grandes y medianos de América Latina.

En lo referente a inestabilidad política, hay una diferencia importante entre ambos países. La democracia prevaleció en Chile entre 1932 y 1973 y sólo dos presidentes elegidos gobernaron el país en los años 60. Por el contrario, los intermitentes ciclos económicos de Argentina y la proscripción del partido peronista de la competencia electoral a partir de 1955 fueron causa de una importante inestabilidad política. Entre 1955 y 1963, el país tuvo cinco presidentes y sólo uno fue elegido de manera democrática. En 1962, el presidente democrático en ejercicio, Arturo Frondizi, fue derrocado por otro golpe de estado. Durante dos años el senador Guido, títere de los militares, cumplió el rol de presidente provisional. El siguiente gobierno civil también fue de corta duración. El presidente Illia fue elegido en 1963 y derrocado por un golpe militar en 1966. Desde entonces, tres generales alternaron en el poder. La agitación social y la creciente violencia política llevaron a Onganía a dimitir en 1970 (Bozzoli, della Paolera y Irigoin, 2003:51).

La inestabilidad de la política argentina también se vinculaba con los conflictos entre grupos empresariales y con la intervención de las fuerzas armadas (Barbero y Rocchi, 2003). Si bien la heterogeneidad no era una característica privativa del empresariado argentino, a partir del surgimiento del peronismo fue incrementándose la fragmentación del sector industrial, corporizada en la existencia de múltiples cámaras y asociaciones representativas de intereses puntuales y en la transformación de una lucha interindustrial en una lucha política (Acuña et al. 1988: 210-211). Ben Ross Schneider (2004) también considera que la politización de las gremiales empresarias se intensificó con la llegada del peronismo al poder y continuó tras su caída. Asimismo, el programa adoptado por el régimen de Onganía causó nuevas y más agudas fricciones entre las empresas (y con el gobierno). Una clara demostración de estos conflictos tuvo lugar en 1967, cuando las industrias más grandes del país, incluyendo las multinacionales, retiraron su participación activa en la UIA (Unión Industrial Argentina) y crearon el Consejo Empresario Argentino. Al mismo tiempo, la UIA comenzó a alejarse de la posición liberal, se hizo más afín al nacionalismo económico y criticó la "desnacionalización" de la industria argentina durante la dictadura de Onganía (Brennan 2007). Por lo tanto, este periodo se destacó por una situación en la cual las centrales 
empresarias, por un lado, estaban enfrentadas entre sí, y por otro, se alinearon con distintos gobiernos, y en que las posiciones divergentes de sus integrantes se alineaban con respecto al peronismo y más en general acerca del rol del Estado en la economía y con la dominante presencia de empresas multinacionales en la estructura industrial.

Otro factor que distingue a los últimos años de la década del sesenta fue la creciente polarización ideológica y política entre distintos sectores de las sociedades chilena y argentina (Solimano, 2004). Argentina sufrió una temprana e impactante escalada de violencia desde mitad de los años sesenta. La violencia se volvió progresivamente la norma $y$, en cierta manera, fue aceptada por gran parte de la sociedad como una forma legítima de resolver conflictos (Romero, 2009). La compleja coyuntura política, caracterizada por un deterioro de los canales institucionales de expresión, creó las condiciones en las cuales empezaron a aparecer las organizaciones guerrilleras de izquierda. ${ }^{6}$ En Argentina, a diferencia de Chile, las empresas y los ejecutivos extranjeros fueron blanco de los grupos guerrilleros, quienes secuestraron a importantes empresarios. En 1965, se producían menos de diez incidentes por mes. Para junio de 1976, antes del último golpe militar, se registraban más de 300 secuestros mensuales (Holmes, 2001). La revista Time calculó que un 60 por ciento de los empresarios extranjeros abandonaron Argentina durante 1973, impulsados por el secuestro de 170 gerentes durante ese año (Gillespie, 1982). Ex ejecutivos argentinos han señalado que la participación en directorios aumentaba la exposición pública y en consecuencia la amenaza de secuestro. En ese sentido, la violencia contra los empresarios puede haber disminuido los incentivos de los miembros de la elite empresarial a participar como miembros de los directorios dañando la creación de vínculos entre las empresas y agregando un nuevo elemento al escenario de incertidumbre descrito previamente (Boyd, 1990).

El escenario empresarial de Chile fue diferente durante el mismo período. Los empresarios chilenos, junto con las principales asociaciones empresariales del país, ejercieron una influencia mucho más significativa en la formulación de políticas públicas que en la Argentina; aspecto que se vio fortalecido por la cohesión y la concentración geográfica de la elite empresarial chilena (Zeitlin y Ratcliff, 1988; Ross Schneider, 2004). Durante la administración de Alessandri Rodríguez, el gobierno estuvo estrechamente relacionado con los intereses empresariales locales,

6 Dos de los grupos más importantes eran los Montoneros Peronistas y el troskista Ejercito Revolucionario del Pueblo (ERP) (Skidmore y Smith 2001). En Chile, por un período similar, el MIR (Movimiento de Izquierda Revolucionaria) se fundó en 1965 y en 1968 pasó a la clandestinidad. Llevó a cabo acciones armadas desde la clandestinidad y trabajó por tomar el poder a partir de la insurrección (hasta la Victoria de Salvador Allende en 1970). 
lo cual garantizaba una continuidad de políticas que favorecían una menor intervención y regulación del estado (Kline, 1992).

En el contexto volátil de la Argentina al final de los años sesenta, se habría reducido aún más la capacidad de las empresas para formular estrategias a largo plazo y el valor de la contribución de los directores ajenos a las empresas (Carpenter y Westphal 2001). Un contexto de toma de decisiones "más ruidoso" y más complejo podría haber dificultado a los directorios recibir y aprovechar la experiencia de los directores externos, con lo cual se habrían reducido los incentivos a incorporar directores múltiples (Shropshire 2010). Los testimonios de directores argentinos que desempeñaron funciones en directorios de aquella época indican que algunas empresas evitaban discutir temas estratégicos en las reuniones de directorio con el objetivo de preservar algo de flexibilidad para responder al cambiante escenario político y económico del país. Debido a esto, la cantidad de vínculos entre las empresas habría disminuido, lo cual habría afectado la estructura de la red de directorios (Mizruchi 1996; Burris 2005). No obstante, esta situación habría contribuido a aumentar la presencia de "técnicos" entre los directores con mayor centralidad, y también a potenciar otro uso de la institución de la sindicatura de empresas (como explicaremos más adelante). Al respecto, es importante considerar que la masiva presencia de empresas extranjeras a partir de 1958 no sólo estuvo asociada a la explotación de un mercado interno protegido, sino también a la existencia de mecanismos de discriminación que requerían de autorizaciones específicas e individuales.

Por lo tanto, proponemos que aunque ambos países estaban inmersos en escenarios turbulentos, el entorno empresarial en Chile, caracterizado por fuerte cohesión de las corporaciones del empresariado, facilitó los vínculos entre empresas a nivel de directorio como una práctica común y un mecanismo efectivo para lograr mayor unidad y coordinación (Mizruchi, 1996; Burris, 2005). En contraposición a Chile, la fuerte politización y enfrentamiento de la clase empresaria argentina, junto al incremento de la violencia política, habría disminuido la existencia de vínculos entre empresas y afectado la cohesión de la red empresarial en Argentina.

\section{Estructuras de propiedad y organizativas}

Si la inestabilidad económica e institucional se convirtió en un componente esencial para explicar la acción de los empresarios, también influyeron las reformas económicas que promovieron cambios en la composición y perfil de las elites económicas de ambos países. Tal como indican estudios previos para otros países, la propiedad y la estructura organizacional de las empresas afecta las redes de directorios (Rinaldi y Vasta, 2005; Khana y Rivkin, 2006; Corrado y Zollo, 2006). 
Por ejemplo, Rinaldi y Vasta (2005) estudiaron la estructura de la red de directorios de todas las sociedades anónimas italianas entre 1952 y 1972, encontrando diferencias entre las estrategias de redes de las grandes corporaciones y aquellas de las empresas de menor tamaño. Bucheli y Salvaj (2011) encontraron diferencias en las estrategias de vinculación entre las subsidiarias de multinacionales, las empresas de grupos económicos chilenos y las empresas del estado en la industria de las telecomunicaciones en Chile. Según este trabajo, los grupos económicos chilenos eran más activos creando relaciones a nivel de directorio.

Las peculiaridades de los capitalismos de Argentina y Chile y el rango y las modalidades de la intervención estatal en la economía generaron hacia finales de la etapa ISI una configuración distinta de la estructura de propiedad de las empresas en ambos países. En particular se distingue la participación diferencial de los grupos económicos locales y de las subsidiarias de multinacionales entre las empresas más grandes de Argentina y Chile. Los rankings por ventas de las 100 mayores empresas de Argentina a comienzos de la década de 1970 proveen un indicador de la importancia relativa de los grupos económicos en relación a otras formas organizacionales como las empresas multinacionales extranjeras, estatales y privadas nacionales que no formaban parte de grupos económicos. Para entonces, la distribución de las 100 mayores empresas por volumen de ventas anuales evidenciaba la participación destacada de las empresas multinacionales extranjeras (con un $52,6 \%$ del total de las ventas) y revelaba un porcentaje similar de empresas estatales y empresas privadas nacionales $(23,4 \%$ y $24 \%$, respectivamente) (Revista Competencia Económica, 1970). En este último grupo existía una participación similar entre firmas pertenecientes a grupos económicos y empresas privadas independientes. Hasta mediados de los 1970 s los grupos económicos argentinos tuvieron un rol menos central en la economía. Asimismo, las empresas pertenecientes a grupos económicos en Argentina no ocupaban puestos dominantes entre las mayores del país, (con la excepción de las del grupo Bunge y Born). No obstante, un trabajo reciente de Lluch, Salvaj y Barbero (2011) postula que las empresas de grupos económicos en Argentina tendieron a generar comparativamente más vinculaciones a nivel de directorio que las empresas más grandes del país.

En forma inversa, los grupos económicos diversificados fueron la forma dominante de estructura empresarial en Chile y la mayoría de las empresas chilenas de mayor tamaño estaban bajo el control de familias (Zeitlin et al 1988). La tabla A2 (en el Apéndice) muestra el tipo de propietarios predominante de las 37 empresas más grandes de Chile en 1966, 30 de 37 empresas eran controladas por familias locales. 
Además, las familias estaban interrelacionadas; prueba de ello es el número de empresas chilenas incluidas en la Tabla 2 controladas por familias asociadas. Chile se caracterizó por una propiedad más concentrada y las grandes empresas eran principalmente controladas y administradas por redes familiares.

El peso diferencial de los grupos económicos locales en una y otra economía puede asociarse también con que las políticas públicas en Argentina en los años sesenta beneficiaron más a las empresas extranjeras que a los grupos nacionales. Los gobiernos de este período tendieron a promover el ingreso de inversiones extranjeras como una estrategia de desarrollo. Durante la administración de Frondizi (1958-1962) dicho proceso alcanzó su clímax. La ley 4.780 sobre inversión extranjera directa promulgada en 1958, estableció condiciones extremadamente favorables para la instalación de empresas multinacionales (Mallon y Sourrouille, 1975). Como consecuencia comenzó a fluir el capital y creció la inversión extranjera, la cual alcanzó los 500 millones de dólares entre 1959 y 1962 (Barbero y Rocchi, 2003). Del total de multinacionales, el 60\% eran estadounidenses, y se concentraban en las industrias química, petroquímica y de petróleo, de transporte, metalúrgica, y de maquinaria eléctrica y mecánica (ver tabla A1 en el Apéndice) (Sourrouille, Kosacoff y Lucangeli, 1985).

Entre 1961 y 1966, cayó la inversión extranjera directa, pero con el advenimiento de Onganía, hubo un cambio en el rol asignado al capital extranjero. En consecuencia, en 1967, 1968 y 1969 el valor de tales autorizaciones fue, respectivamente, 13.1, 31.5 y 59.1 millones de dólares (Sourrouille, 1976). Durante 1967-1969, las inversiones extranjeras estuvieron orientadas al financiamiento de corto plazo y a la compra de empresas argentinas.

Estudios ya mencionados anteriormente confirman que diferencias en el tipo de propiedad conllevan estrategias de vinculación diferenciales en la conformación de directorios e impactan en la estructura de esta red corporativa. Según estos trabajos, los grupos económicos tienden a ser más activos a la hora de generar vínculos a nivel de directorio. Por lo tanto, debido a las diferencias entre las estructuras de propiedad de Chile y Argentina distinguidas por una mayor participación de grupos económicos locales en Chile y de subsidiarias de multinacionales en Argentina, hipotetizamos que el porcentaje de empresas relacionadas a través de sus directorios era mayor en Chile que en Argentina. Adicionalmente, esperamos que el grado promedio de conexiones por empresa sea mayor en Chile que en Argentina. 
Los resultados confirman la hipótesis de que las diferencias en la turbulencia institucional y económica así como también en la estructura de propiedad de las empresas más grandes a fines de los años 60, contribuyeron a otorgar rasgos distintivos en las estructuras de las redes de directorio de Chile y Argentina. Comenzando con un análisis gráfico ${ }^{7}$, la red de directorios de las empresas más grandes de Chile (Figura 1) ilustra que la red chilena era más grande y más densa, mientras que la red argentina (Figura 2) era más fragmentada y dispersa y la parte central más pequeña.

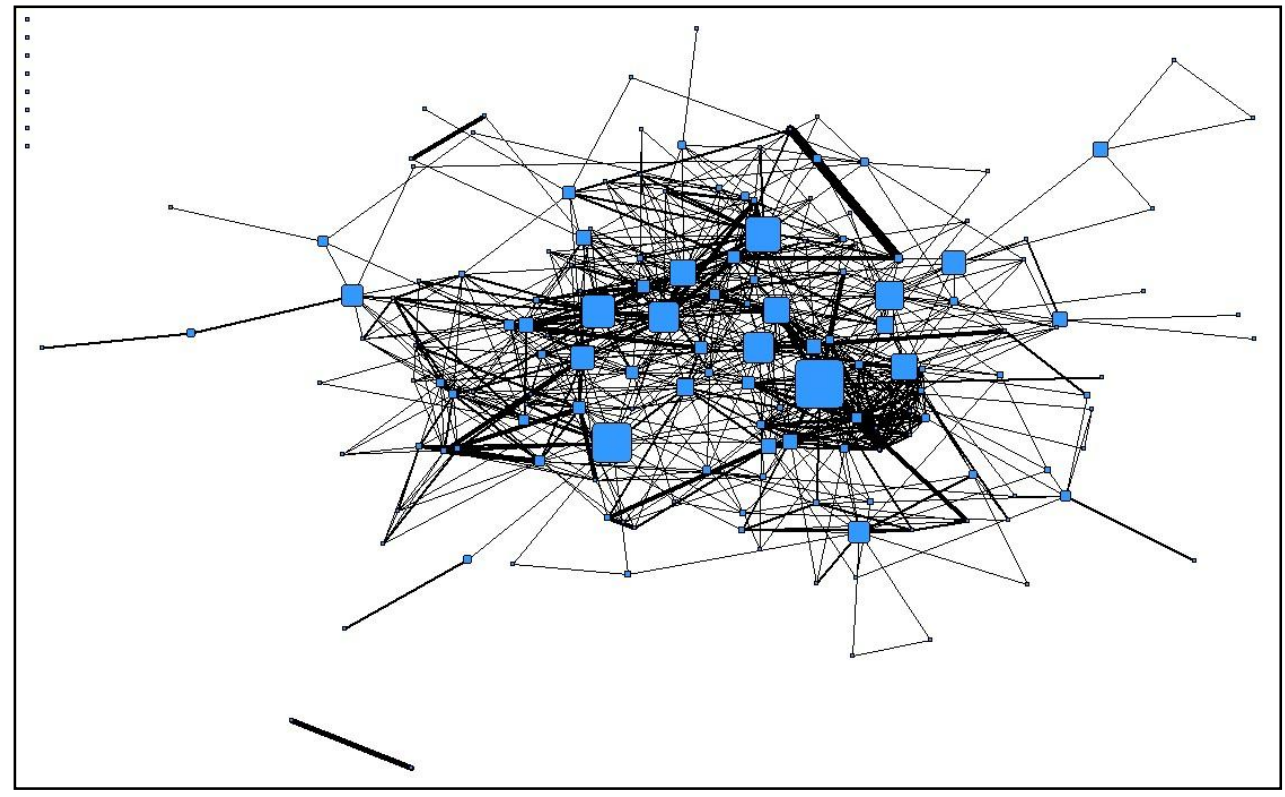

Figura 1: Red de directorios de las empresas más grandes de Chile.

En la figura 1, se observa que la cantidad de relaciones entre directorios era notablemente mayor en el caso chileno, mientras que en la red de directorios argentina existían menos líneas y por lo tanto menos relaciones o directores compartidos. Adicionalmente en la red chilena se observan cliques densos que muestran una mayor cantidad/intensidad de líneas correspondientes a vínculos entre empresas de un mismo grupo económico. Debido a la escasa participación de empresas de un mismo grupo económico en la red de directorios de las empresas de mayores ventas de la Argentina en 1970, estos cliques densos no se visualizan en la figura 2.

\footnotetext{
${ }^{2}$ En estas figuras, los nodos son las empresas y una línea entre dos empresas cualquiera representa los directores que ambas empresas tienen en común. El ancho de la línea representa el número de directores que dos empresas comparten. El tamaño de los nodos varía según la centralidad de intermediación de la red. Mientras más grande es el nodo, más central es la empresa.
} 
Los nodos de mayor tamaño en la figura 1 corresponden a empresas y bancos de grupos económicos chilenos (Ver tabla 2 con datos de centralidad de intermediación). En el caso de la figura 2, los dos nodos de mayor tamaño corresponden a subsidiarias de empresas multinacionales (Ver tabla 2).

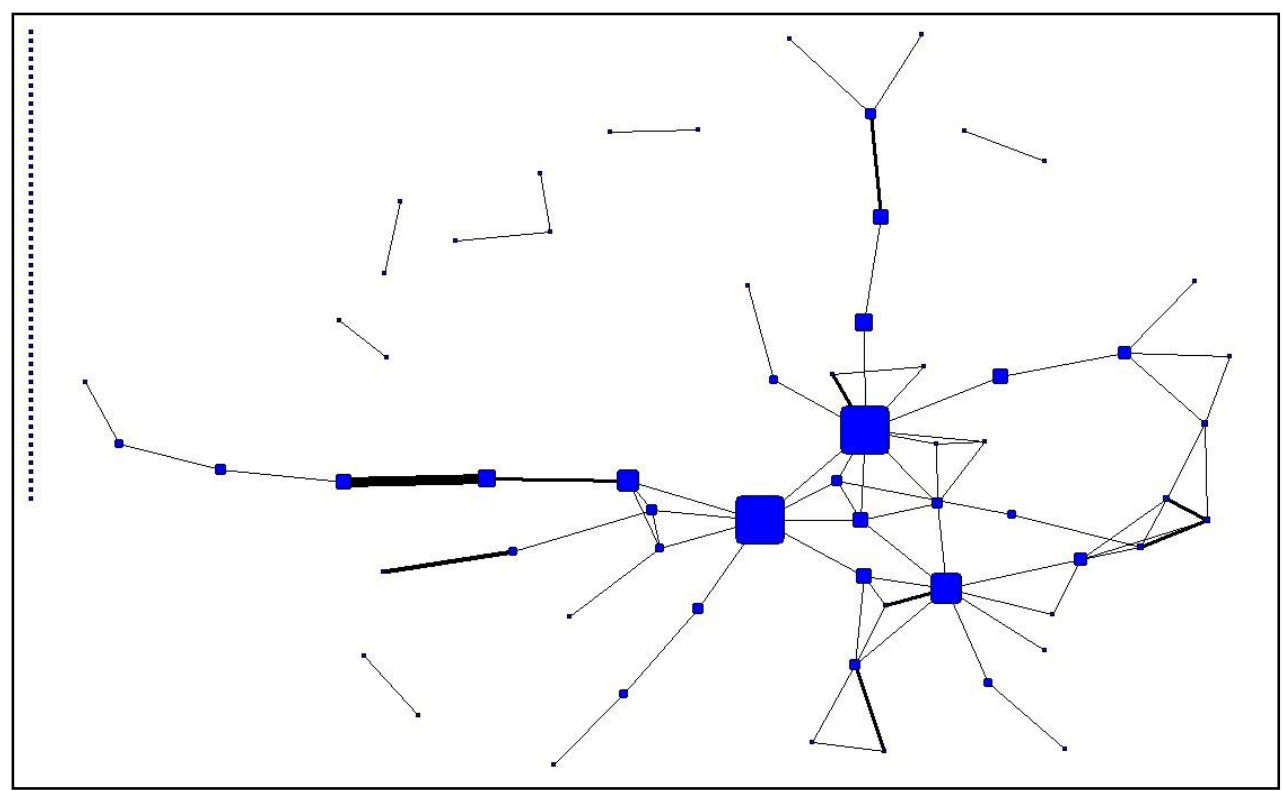

Figura 2: Red de directorio de las empresas más grandes de Argentina

Los resultados gráficos son ratificados por los parámetros estructurales sintetizados en la Tabla 1. Nuestra muestra contiene 116 empresas argentinas y 165 empresas chilenas (Ver en Apéndice detalles de las fuentes de datos y la tabla A3 con clasificación de todas las empresas de acuerdo con las distintas industrias y tipo de propiedad).

En la línea 4 de la Tabla 1 se detalla el número de empresas financieras. Las 33 empresas financieras argentinas tenían 272 directores y las 25 empresas financieras chilenas nombraron 211 directores (ver línea 5). La línea 6 muestra que el sistema argentino tenía más directores (861) que el chileno (588), a pesar de que la cantidad de empresas argentinas era menor y que Argentina tenía en promedio directorios más pequeños (8) que Chile (9) (Ver línea 7).

Las líneas 8 y 9 registran el número y porcentaje de empresas conectadas y aisladas, respectivamente. El porcentaje de empresas aisladas en Argentina era del $46 \%$, mientras que en Chile era sólo de un $6 \%$. El resultado demuestra que la red de Argentina era más fragmentada y dispersa. El número de empresas marginales (empresas con sólo uno o dos vínculos) y aisladas (sin conexiones) era también mayor en Argentina (76\%) que en Chile (20\%) ( líneas 10 y 11 ). 
El número de empresas en el componente principal se indica en la línea 12 (aquí sólo se incluye a empresas que comparten miembros de directorio y por tanto no se consideran las empresas sin relaciones o aisladas). La parte central de la red argentina incluía sólo un $43 \%$ de las empresas mientras que en Chile casi la totalidad de las mismas, 94\% forman parte de ella. La línea 13 pondera el número de empresas que permanecen en la red al quitar los vínculos menores a 2 (menos de dos directores comunes, este procedimiento se denomina $2 \mathrm{~m}$-slices). En Argentina sólo 16 empresas permanecían cuando se remueven estos vínculos, mientras que en Chile el número se elevaba a 97 empresas. Esta es una nueva muestra de la mayor fragmentación de la red Argentina con respecto a la de Chile.

También comparamos el número de vínculos y la densidad de las redes argentina y chilena y de los componentes principales (ver líneas 14 a 16). El número total de líneas es 81 en Argentina y 755 en Chile. Un 6\% del total de conexiones posibles entre empresas argentinas tuvo lugar dentro del núcleo de la red (o componente principal). Cuando consideramos todos los vínculos, la densidad aumentó a 7,2 \%. En el caso de Chile, dichos porcentajes fueron $5.6 \%$ y $8.1 \%$, respectivamente.

Si consideramos los vínculos indirectos, o la estructura de comunicación de la red, debemos mirar el diámetro y la distancia promedio entre pares de empresas. El diámetro es decir, la longitud entre los dos nodos más distantes pero conectados de la red y la distancia promedio eran más altas en Argentina que en Chile, lo cual refleja la menor cohesión de la red empresarial de Argentina (ver líneas 17 y 18).

El grado promedio de la red y del componente principal es más alto en Chile que en Argentina. El grado promedio es mejor indicador que la densidad como medida de la cohesión general porque no depende del tamaño de la red. Por lo tanto el grado promedio puede ser comparado entre redes de diferentes tamaños. Mientras que en Argentina el grado promedio de la red fue de 1,6; en Chile fue de 11, 5 (ver líneas 19 y 20 en la tabla 1). Estos resultados demuestran que las empresas chilenas se apoyaron con mayor fuerza en las redes de directorio como herramientas de coordinación y control.

\begin{tabular}{|c|l|c|c|}
\hline & \multicolumn{1}{|c|}{ País } & Argentina & Chile \\
\hline & \multicolumn{1}{|c|}{ Año } & 1970 & 1970 \\
\hline 1 & Total de la Muestra & 116 & 165 \\
\hline 2 & Número de empresas no-financieras & 83 & 140 \\
\hline 3 & Número total de directores en emp. no financieras & 589 & 377 \\
\hline 4 & Número de empresas financieras & 33 & 25 \\
\hline 5 & Número total de directores en emp. financieras & 272 & 211 \\
\hline 6 & $\begin{array}{l}\text { Número total de directores en empresas financieras e } \\
\text { industriales }\end{array}$ & 861 & 588 \\
\hline 7 & Tamaño promedio del directorio & 8 & 9 \\
\hline
\end{tabular}




\begin{tabular}{|c|l|c|c|}
\hline 8 & Número y porcentaje de empresas conectadas & $63(54 \%)$ & $157(95 \%)$ \\
\hline 9 & Número y porcentaje de empresas aisladas & $52(46 \%)$ & $8(6 \%)$ \\
\hline 10 & Número y porcentaje de empresas marginales & $35(30 \%)$ & $25(15 \%)$ \\
\hline 11 & $\begin{array}{l}\text { Porcentaje de empresas aisladas y marginales con } \\
\text { respecto al número total de empresas }\end{array}$ & $76 \%$ & $20 \%$ \\
\hline 12 & Porcentaje de empresas en el componente principal & $50(43 \%)$ & $155(94 \%)$ \\
\hline 13 & Número de empresas en 2m-slices & $16(14 \%)$ & $97(59 \%)$ \\
\hline 14 & Número total de líneas & 81 & 755 \\
\hline 15 & Densidad (componente principal y dicotomizada) & $6 \%(74$ líneas) & $\begin{array}{c}5.6 \%(755 \\
\text { líneas) }\end{array}$ \\
\hline 16 & Densidad (componente principal) & $7.2 \%$ & $8.1 \%$ \\
\hline 17 & Diámetro del componente principal & 11 & 7 \\
\hline 18 & Distancia promedio del componente principal & 4.269 & 2.838 \\
\hline 19 & Grado promedio de la red & 1.638 & 11.539 \\
\hline 20 & Grado promedio del componente principal & 2.96 & 12.232 \\
\hline 21 & Número de directores compartidos & 63 & 159 \\
\hline 22 & Número de grandes conectores & 11 & 74 \\
\hline 23 & $\begin{array}{l}\text { Porcentaje de directores compartidos con respecto al } \\
\text { total de directores. }\end{array}$ & $7 \%$ & $27 \%$ \\
\hline 24 & $\begin{array}{l}\text { Porcentaje de grandes conectores con respecto al } \\
\text { total de directores }\end{array}$ & $1 \%$ & $13 \%$ \\
\hline
\end{tabular}

Tabla 1: Parámetros estructurales.

Los directores compartidos (aquellos directores que son miembros de uno o más directorios) y los grandes conectores (directores que participan en tres o más directorios) son una señal de redundancia en la red y de utilización de las relaciones a nivel de directorio como práctica de coordinación y control (ver líneas 21 a 24). El porcentaje de directores múltiples era menor en Argentina (7\%) que en Chile (27\%), según lo muestra la línea 23. Asimismo el porcentaje de grandes conectores era mayor para el caso de Chile (13\%) que en Argentina (1\%). La mayor redundancia de la red chilena proporcionó más oportunidades para ejercer el control a través de la red de directorios.

En suma, los resultados sintetizados en la tabla 1 confirman nuestras hipótesis. Si bien ambos países aplicaron estrategias ISI de desarrollo económico y enfrentaron situaciones de turbulencia económica y social, la Argentina se caracterizó por una estructura de propiedad con una alta presencia de empresas multinacionales, un escenario económico más inestable, una mayor conflictividad política y una comunidad empresaria mucho menos cohesionada que la chilena a finales de los años 60s. Dichas condiciones externas afectaron la estructura de red de directorios de Argentina reduciendo el número promedio de directores compartidos por empresa y aumentaron la fragmentación de la red. Por el contrario, el escenario político más estable de Chile (hasta 1970), la cohesiva elite empresarial y la mayor participación de los grupos económicos locales generaron una mayor cantidad de vínculos a nivel de directorio entre las empresas chilenas y produjeron una densa red de entrecruzamiento de directorios. 


\section{Centralidad de los distintos actores}

Las diferencias en la estructura de la red de directorios también impactaban en el rol o lugar que las empresas ocupaban en la misma. Diversas medidas de centralidad nos permiten entender el rol que jugaban los distintos tipos de empresas en la red de directorios de Argentina y Chile a fines de la década de 1960 (Ver en apéndice la definición de medidas de centralidad).

El rol de los Grupos Económicos

En función de los argumentos expuestos en la sección anterior, y si nos focalizamos en la centralidad de intermediación, detectamos que en Chile nueve de las diez empresas más centrales pertenecían a grupos económicos locales. Las empresas de los grupos económicos chilenos en su mayoría se encontraban entre las más grandes del país y eran muy activas a la hora de generar relaciones a nivel de directorio. Tres empresas se destacaban en el ranking: Compañía Cervecerías Unidas (bebidas), Chilena Consolidada de Seguros de Vida (seguros) y Banco Edwards que estaban bajo el control del grupo económico Edwards (perteneciente a una familia de origen inglés con influencia financiera y política que ha desempeñado un rol importante en la política chilena, especialmente como dueños del periódico más influyente, El Mercurio). Empresas Copec era controlada por el grupo económico Bulnes, el grupo económico Banco Hipotecario y las familias Castillo y Ricardo Claro. Completan la lista Cementos Bio Bio (Grupo Económico Briones), Ganadera Tierra del Fuego (familias tradicionales del sur de Chile), Banco de Chile (grupo de inversores minoritarios), Banco Español de Chile, (controlado por las familias García y Pico) y el Banco Panamericano (Grupo Económico Said). En Chile, una sola empresa propiedad de una multinacional, la Cía. de Telecomunicaciones de Chile, participaba del ranking por centralidad de intermediación. Por el contrario, en el caso de Argentina sólo dos empresas en el ranking son de propiedad de grupos económicos locales: Loma Negra y Celulosa (cuya propiedad estaba vinculada con el denominado Grupo Fabril). 


\begin{tabular}{|c|c|c|c|c|c|c|c|}
\hline \multicolumn{4}{|c|}{ Chile } & \multicolumn{4}{|c|}{ Argentina } \\
\hline Empresa & C. Int. & Industria & Propiedad & Empresa & C. Int. & Industria & Propiedad \\
\hline Cementos Bio Bio & 4,826 & Cemento & $\begin{array}{l}\text { Familia } \\
\text { chilena }\end{array}$ & $\begin{array}{c}\text { Siemens } \\
\text { Argentina } \\
\end{array}$ & 2,05 & $\begin{array}{c}\text { Prod. } \\
\text { Electric. }\end{array}$ & Extranjera \\
\hline $\begin{array}{c}\text { Compañía } \\
\text { Cervecerías } \\
\text { Unidas }\end{array}$ & 4,898 & Bebidas & $\begin{array}{l}\text { Familia } \\
\text { chilena }\end{array}$ & $\begin{array}{c}\text { Pasa } \\
\text { Petroquímica }\end{array}$ & 2,06 & Química & Extranjera \\
\hline \begin{tabular}{|c|} 
Ganadera Tierra \\
del Fuego
\end{tabular} & 5,033 & $\begin{array}{c}\text { Agronegocio } \\
\mathrm{s}\end{array}$ & $\begin{array}{l}\text { Familia } \\
\text { chilena }\end{array}$ & Duperial & 2,11 & Química & Extranjera \\
\hline Empresas Copec & 5,709 & $\begin{array}{c}\text { Forestación/ } \\
\text { Petróleo }\end{array}$ & $\begin{array}{l}\text { Familia } \\
\text { chilena }\end{array}$ & $\begin{array}{c}\text { Bco Nacional } \\
\text { del Desarrollo }\end{array}$ & 2,11 & Bancaria & Estatal \\
\hline \begin{tabular}{|c|} 
Chilena \\
Consolidada de \\
Seguros de Vida \\
\end{tabular} & 5,932 & Seguros & $\begin{array}{l}\text { Familia } \\
\text { chilena }\end{array}$ & $\begin{array}{l}\text { Bco. Popular } \\
\text { de Quilmes }\end{array}$ & 2,75 & Bancaria & Argentina \\
\hline $\begin{array}{c}\text { Cia. Telecom. de } \\
\text { Chile }\end{array}$ & 5,955 & Telecom & Extranjera & Electrolor & 2,75 & Química & $\begin{array}{l}\text { Argentina/ } \\
\text { Extranjera }\end{array}$ \\
\hline Banco de Chile & 6,537 & Bancaria & Chilena & $\begin{array}{l}\text { Celulosa } \\
\text { Argentina }\end{array}$ & 3,36 & $\begin{array}{c}\text { Papel/Fore } \\
\text { st. }\end{array}$ & Argentina \\
\hline Banco Edwards & 7,090 & Bancaria & $\begin{array}{l}\text { Familia } \\
\text { chilena }\end{array}$ & Loma Negra & 5,13 & Cemento & $\begin{array}{c}\text { Familia } \\
\text { Argentina }\end{array}$ \\
\hline $\begin{array}{c}\text { Bco. Español de } \\
\text { Chile }\end{array}$ & 7,969 & Bancaria & $\begin{array}{l}\text { Familia } \\
\text { chilena }\end{array}$ & $\begin{array}{c}\text { Cristalerias } \\
\text { Rigolleau }\end{array}$ & 8,41 & \begin{tabular}{|c|} 
Vidrio y \\
Embalajes \\
\end{tabular} & Extranjera \\
\hline $\begin{array}{c}\text { Bco } \\
\text { Panamericano }\end{array}$ & 10,094 & Bancaria & $\begin{array}{l}\text { Familia } \\
\text { chilena }\end{array}$ & Minera Aguilar & 8,53 & Minería & Extranjera \\
\hline
\end{tabular}

Tabla 2: Directorios con mayor centralidad de intermediación

Como complemento se llevó a cabo el test de Mann Whitney. En este análisis excluimos a las empresas sin redes de directorios; la muestra final incluía 50 empresas argentinas y 155 empresas chilenas (estos valores corresponden a las empresas que forman parte del componente principal). En primer lugar, queríamos comparar si existían diferencias en la centralidad entre las empresas de grupos económicos o familiares y empresas que no pertenecían a grupos locales o familiares en Chile y en Argentina. La tabla 3 presenta los resultados. Nuevamente, encontramos que las empresas de grupos económicos chilenos o de familias chilenas eran significativamente más centrales (en todas las medidas de centralidad) que las empresas que no pertenecían a grupos o familias. Por el contrario, en Argentina, las empresas de propiedad de grupos económicos y familiares no son significativamente más centrales que las empresas que tienen otro tipo de propietario (los resultados se detallan en las columnas 1 y 2 de la tabla 3). 


\begin{tabular}{|c|c|c|c|c|c|c|c|c|c|c|c|c|}
\hline & \multicolumn{4}{|c|}{$\begin{array}{c}\text { Empresas de propiedad } \\
\text { de grupos } \\
\text { económicos/familias }\end{array}$} & \multicolumn{4}{|c|}{$\begin{array}{l}\text { Empresas de propiedad } \\
\text { extranjera o empresas } \\
\text { locales }\end{array}$} & \multicolumn{4}{|c|}{$\begin{array}{c}\text { Instituciones financieras y } \\
\text { no financieras }\end{array}$} \\
\hline & \multicolumn{2}{|c|}{ Chile (1) } & \multicolumn{2}{|c|}{$\begin{array}{l}\text { Argentina } \\
(2)\end{array}$} & \multicolumn{2}{|c|}{ Chile (3) } & \multicolumn{2}{|c|}{$\begin{array}{l}\text { Argentina } \\
\text { (4) }\end{array}$} & \multicolumn{2}{|c|}{ Chile (5) } & \multicolumn{2}{|c|}{$\begin{array}{l}\text { Argentina } \\
(6)\end{array}$} \\
\hline & \multicolumn{2}{|c|}{$\begin{array}{c}\text { Componente } \\
\text { principal }\end{array}$} & \multicolumn{2}{|c|}{$\begin{array}{c}\text { Componente } \\
\text { principal }\end{array}$} & \multicolumn{2}{|c|}{$\begin{array}{c}\text { Componente } \\
\text { principal }\end{array}$} & \multicolumn{2}{|c|}{$\begin{array}{c}\text { Componente } \\
\text { principal }\end{array}$} & \multicolumn{2}{|c|}{$\begin{array}{c}\text { Componente } \\
\text { principal }\end{array}$} & \multicolumn{2}{|c|}{$\begin{array}{c}\text { Componente } \\
\text { principal }\end{array}$} \\
\hline Variable & $\left|\begin{array}{c}\text { Z- } \\
\text { score }\end{array}\right|$ & Sig. & $\begin{array}{c}\text { Z- } \\
\text { score }\end{array}$ & Sig. & \begin{tabular}{|c|} 
Z- \\
score
\end{tabular} & Sig. & $\begin{array}{c}\text { Z- } \\
\text { score }\end{array}$ & Sig. & $\begin{array}{c}\text { Z- } \\
\text { score }\end{array}$ & Sig. & $\begin{array}{c}\text { Z- } \\
\text { score }\end{array}$ & Sig. \\
\hline $\begin{array}{l}\text { Centralida } \\
\text { d } \quad \text { de } \\
\text { Grado }\end{array}$ & -3.2 & $\begin{array}{r}0.0014 \\
* *\end{array}$ & -0.287 & 0.7742 & 1.387 & 0.1655 & -0.594 & 0.5525 & $\mid-1.524$ & 0.1275 & 1.628 & 0.1034 \\
\hline $\begin{array}{|lr|}\text { Centralida } \\
\text { d } & \text { de } \\
\text { Intermedi } \\
\text { ación }\end{array}$ & 1.842 & $\begin{array}{r}0.0655 \\
*\end{array}$ & 1.234 & 0.2173 & 1.324 & 0.1854 & -0.28 & 0.7797 & -3.335 & $0.0009 *$ & 0.06 & 0.9519 \\
\hline $\begin{array}{l}\text { Cent. } \\
\text { Global de } \\
\text { grado }\end{array}$ & $=3.372$ & $\begin{array}{r}0.0007 \\
* *\end{array}$ & 0.574 & 0.5662 & 1.559 & 0.119 & -1.213 & 0.2251 & -0.51 & 0.6104 & 1.453 & 0.1464 \\
\hline \# de obs. & 155 & & 50 & & 155 & & 50 & & 155 & & 50 & \\
\hline
\end{tabular}

+ significativo a nivel $10 \%, *$ significativo a nivel $5 \%, * *$ significativo a nivel $1 \%$.

Tabla 3: Prueba Mann Whitney

El rol de las Multinacionales

Según se mencionó anteriormente, las empresas multinacionales tuvieron un rol más decisivo en el desarrollo industrial de Argentina durante ISI que el que tuvieron en Chile. Como consecuencia de las políticas de promoción de inversión extranjera directa mencionadas, las multinacionales incrementaron su importancia en la economía. La participación en las ventas de las empresas extranjeras considerando las 100 empresas argentinas más grandes fue de 63.3\% en 1957, $76.6 \%$ en 1962 y 79.4\% en 1969 (Khavisse \& Piotrkowski, 1973). Las empresas extranjeras, en particular las más grandes, operaban en mercados con un alto grado de concentración y escasa participación de empresas locales privadas (al menos hasta 1970) (Azpiazu y Kosacoff, 1985).

En contraposición a esta situación, en Chile la inversión extranjera tomó el control de las actividades mineras más importantes. Durante el siglo veinte, hasta un $90 \%$ de la inversión extranjera se concentraba en la minería, especialmente en el cobre. Las empresas extranjeras también invirtieron en empresas de servicios eléctricos y de servicio telefónico; sin embargo, a pesar del crecimiento relativo de algunas inversiones, las multinacionales no dominaron el sector de industrias livianas del país. Los recursos naturales de Chile explican en gran medida este patrón, junto al pequeño mercado de consumo del país el cual no constituía un gran atractivo para los inversores extranjeros (Kline, 1992). Como ya ha sido expuesto, el rol de los grupos económicos locales fue más decisivo que el de las multinacionales en el caso 
de Chile, a pesar de la ocasional imposición al gobierno local de prioridades relacionadas con gobiernos extranjeros (principalmente de EEUU) Aunque los intereses económicos extranjeros y nacionales coincidieron a menudo, especialmente en los límites a la intervención estatal en la economía, cuando hubo alguna divergencia, los grupos económicos influenciaron con éxito a varios gobiernos chilenos a hacer un giro hacia políticas más favorables para las empresas locales (Kline, 1992). Teniendo en cuenta este rol menos predominante de las multinacionales en el sector industrial en Chile, es esperable que las empresas multinacionales fueran más centrales en Argentina que en Chile para 1970.

Esto se confirma al analizar los datos que se detallan en la tabla 2, pues dentro de las diez empresas más centrales en Argentina se destacan seis empresas de propiedad extranjera, mientras que en Chile hay una sola empresa extranjera en el ranking. Esta conclusión también sugiere que las multinacionales se integraron a las redes empresariales argentinas y se ubicaban entre las empresas más conectadas, pero no estaban significativamente más conectadas que las empresas locales (Ver Tabla 3, columna 4).

El estudio también reveló que el nivel de internacionalización o interconexiones entre los directorios argentinos y chilenos era muy bajo a finales de los sesenta. Sólo encontramos dos directores, Fernando Carlés y Felix Van de Walle, ocupando puestos en directorios a ambos lados de los Andes. Las empresas argentinas y chilenas que compartían un director eran de propiedad de empresas estadounidenses. Cristalerías Rigolleau y Cristalerías de Chile estaban bajo el control de Corning Glass; Embotelladora Andina y Coca Cola Argentina bajo el de Coca Cola y Squibb era una subsidiaria de una empresa farmacéutica de Estados Unidos.

\section{El rol de los Bancos}

La literatura ha resaltado dos modelos dominantes respecto del rol de los bancos en las redes empresariales (Davis y Mizruchi, 1999). En primer lugar, se postula que "las redes de directorio son un medio de control que permite a los bancos crear grupos de interés de empresas que van a servir a los intereses de los bancos. Este poder deriva de su calidad de entidades crediticias y de grandes accionistas". El segundo modelo remarca "las relaciones recíprocas entre los bancos y las industrias, donde la coordinación, y no la dominación, es el modo imperante de relación; las conexiones banco-industria son mutuas y no dirigidas desde el primer sector al segundo. Este modelo presenta las redes de directorio como una 
expresión de cohesión dentro de la clase dirigente y un medio por el cual se mantiene y se promueve dicha unidad.

Nuestra investigación encontró que los bancos en Chile ocupaban un rol central y de coordinación en la elite corporativa, algo que no se replicaba para el caso argentino. Según lo muestra la tabla 2, cuatro bancos aparecían entre las empresas más centrales en la red chilena (Banco Panamericano, Banco EspañolChile, Banco Edwards, y Banco de Chile). El ranking argentino sólo incluye a dos (Banco Popular de Quilmes y Banco Nacional de Desarrollo). En la Argentina, la evidencia indica que los bancos tuvieron un rol menos importante como conectores de las redes empresariales. ¿Qué explicaría su ausencia como grandes conectores? En forma sintética, ello se vincularía con dos rasgos: 1) la estructura de propiedad de las empresas (analizada previamente) y 2 ) el modelo de financiamiento empresarial. En Argentina, el mercado de capitales no era una fuente importante de financiamiento para las empresas, e incluso se debilitó su participación en los 1960s, afectado por la alta volatilidad de la economía. Tampoco la banca privada ofreció financiación a largo plazo para el sector industrial. La diversificación hacia las finanzas fue menos generalizada en los grupos económicos surgidos en los 1960s, y ninguno de los grupos surgidos en el período posterior a la Segunda Guerra Mundial se organizó alrededor de un banco, aunque el grupo Techint tenía inversiones financieras y otros grupos tenían amplios contactos con bancos privados y empresas financieras.

La escasa relevancia de la financiación privada podría deberse a que la principal fuente de financiamiento para las empresas provino de las operatorias crediticias de largo plazo facilitadas por el Banco Industrial de la República Argentina (BIRA1944), y luego por el Banco Nacional de Desarrollo (Banade-1970) y de los préstamos internacionales facilitados por instituciones como el Banco Interamericano de Desarrollo y el Banco Mundial. Ya para 1953, el BIRA concentraba la mitad de los créditos industriales. A través de la acción de los bancos oficiales, el Estado incrementó su participación en la economía pero no sólo como proveedor crediticio sino también como administrador de empresas estatales y privadas. La creciente participación del Estado en el capital social de las empresas privadas obedeció a debilidades estructurales de las firmas, especialmente de tipo financieras (Rougier, 2004). En otras ocasiones, la participación del Estado en el paquete accionario de firmas privadas derivó de decisiones de las autoridades económicas de impulsar ciertas empresas. 
En contraposición, los bancos de desarrollo en Chile no desempeñaron el mismo rol. En 1965, un nuevo decreto (Nro. 16.253) permitió la creación de este tipo de bancos. Sin embargo, se impusieron una serie de restricciones, y el primer banco se fundó recién a fines de 1974. Desde 1968, el Banco Estado estaba autorizado a operar como banco de desarrollo. Si bien la demanda de créditos a mediano y largo plazo era alta, el volumen de dichos créditos fue bajo debido a los escasos incentivos para atraer fondos de largo plazo (Behrens Fuchs, 1985). En Chile, el mercado de valores también estuvo poco desarrollado como fuente de capital. Couyoumdjian, Millar \& Tocornal (1993), sugieren que eran raros los casos de empresas que cotizaran sus acciones para atraer recursos provenientes de inversores externos. En este contexto, los mercados de capitales no tuvieron un papel importante en la asignación de recursos, y en consecuencia, el período entre 1920 y 1970 se caracterizó por una disminución continua tanto en el nivel de transacciones en el mercado de valores como en el valor del mercado sobre el PBI (Islas, 2010).

Lefort y Walker (2000a) argumentan que la represión financiera y el racionamiento del crédito en Chile durante una gran parte del siglo veinte, sentaron las bases para el uso extensivo de mercados de capital internos y la subsiguiente aparición de grupos organizados alrededor de instituciones financieras. Las empresas de grupos económicos tenían por tanto acceso a financiamiento barato a través de bancos relacionados (Lefort, 2010). La banca privada estaba controlada por grupos económicos, que también controlaban empresas monopólicas u oligopólicas en otros sectores de la economía. Por ejemplo, el grupo económico Yarur Banna poseía más del 50\% del Banco de Crédito e Inversiones y controlaba el Banco Llanquihue y el Banco Continental; el Banco Nacional del Trabajo y el Banco Panamericano estaban en el centro del grupo económico Said (con intereses en la industria textil); el Banco Edwards estaba bajo el control de la familia del mismo nombre. El grupo económico relacionado a la familia Matte, era propietario del Banco Sudamericano y la familia Litvak Decepter era dueña del Banco Israelita. El banco privado más importante, el Banco de Chile, estaba en el centro de intensas luchas financieras de varios clanes dado que muchos grupos económicos eran parte de su estructura de propiedad (Behrens Fuchs, 1985).

Un mecanismo que facilitó el control de los bancos por parte de los grupos económicos fueron las redes de directorios. Los bancos chilenos estaban en el centro de los grupos económicos y los directores de instituciones financieras tenían una gran participación en los directorios de varias empresas en Chile. En 1968, 52 directores de los cinco bancos más grandes ocupaban 316 posiciones como miembros de directorios; un director del Banco de Chile en 1970 también era 
director de otras 13 empresas; y en el mismo banco cada director era representante de al menos otras tres empresas. Cuando llevamos a cabo el test de Mann Whitney, encontramos diferencias importantes en la centralidad de intermediación de los bancos chilenos. La tabla 3 (columna 5) refleja la centralidad de intermediación de los bancos e instituciones no financieras en Chile. En resumen, encontramos que los bancos eran más centrales en las redes de directorio chilenas y que los bancos privados tenían un rol de intermediación y coordinación que sus equivalentes argentinos no poseían.

\section{Los Grandes Conectores}

La centralidad de una empresa se explica porque en su directorio participaban directores que ocupaban posiciones similares en varias compañías. A estos individuos se los conoce como directores múltiples o grandes conectores. ¿Quiénes y cuántos eran estos grandes conectores de las redes analizadas? Los directores múltiples o grandes conectores eran más comunes en Chile que en Argentina (Ver tabla 1, líneas 21 a 24). La Tabla A4 (en el apéndice) lista a los grandes conectores en ambos países.

El ranking de Chile estaba dominado por empresarios, expresión de un tipo de director múltiple más clásico y ampliamente analizado en la literatura. Los empresarios actuaban como "conectores", revelando relaciones de control sobre empresas de su propiedad. Por ejemplo, Eliodoro Matte, el director con mayor centralidad de intermediación de Chile a fines de los años 60, se sentaba en el directorio del banco y de varias empresas de su propio grupo económico así como en otras empresas, tales como el Banco Sud Americano, Aceros Andes, de Renta Urbana Pasaje Matte, Empresas CMPC, Empresas Industrial El Melón, Minas y Fertilizantes, Ganadera Tierra del Fuego, Forestal Const. y Comercializadora del Pacífico Sur y ABN AMRO Chile Seguros de Vida. En Argentina, este tipo de director múltiple era mucho menos común y en particular se distingue a Enrique Roberts, el director argentino con más centralidad de intermediación (Ver Tabla A4), quien participaba en los directorios de: Alpargatas, Cristalerías Rigolleau, Banco Francés del Río de la Plata y Minera Aguilar (listadas entre las 100 mayores empresas), y otras empresas no consideradas en este análisis. En ambos casos este conector se distinguía por sus importantes vinculaciones con el sector bancario-financiero derivado del propio perfil de su grupo de pertenencia (el Grupo Roberts).

No obstante, en términos comparativos, los empresarios tenían una menor participación como grandes conectores en Argentina. De hecho, 14 de veinte directores eran ingenieros, abogados, funcionarios de gobierno o contadores públicos que no poseían el control mayoritario de ninguna de las empresas en las 
que participaban como directores. Asimismo, varios de ellos ocuparon cargos de segundo rango o asesorías en distintos gobiernos, en particular en regímenes militares y con orientación pro-empresarial. Ello nos lleva a proponer que un atributo común de los grandes conectores en Argentina era su perfil más técnico y que su participación podría haberse asociados con generar vínculos de otro tipo con los gobiernos de turno y brindar información estratégica a las empresas. Dichas personas sabían cómo navegar a través de las condiciones cambiantes creadas por la inestabilidad política y económica, los poderosos sindicatos, las diversas reglamentaciones económicas, los distintos planes económicos de estabilización y las prácticas idiosincrásicas de asignación de créditos (Guillen,2000:367). No obstante, es interesante destacar que estos individuos eran hombres de poca exposición pública a fines de 1960, aspecto que a partir de entonces habría sido algo buscado por los empresarios debido al incremento de la violencia política.

Abogados, ingenieros y contadores se especializaban en proporcionar una amplia variedad de servicios profesionales y en ayudar a las empresas multinacionales a lidiar con barreras institucionales. Estos factores explicarían que los abogados y los contadores públicos (muchas veces en su calidad de síndicos) ${ }^{8}$ y los funcionarios del gobierno desempeñaron un rol más importante en la red argentina que sus equivalentes chilenos. En efecto, nuestros hallazgos parecen coincidir en parte con los de Bearden and Mintz (1992:192) que advierten que en Estados Unidos los directores externos (es decir, los que no participan activamente en la administración del día a día de la empresa y no poseen una parte importante del capital) eran responsables de la cohesión y unidad de la red, con la particularidad de que en Argentina no habrían sido otros empresarios sino profesionales del derecho, la economía o ingenieros. Por ello postulamos que en el problemático entorno empresarial argentino, las empresas $-y$ particularmente las multinacionales- habrían preferido incluir en sus directorios a determinados tipos de directores -con un perfil más técnico- y otorgado un rol particular a los síndicos, expresiones de distintas estrategias de adaptación a un contexto económico e institucional complejo e inestable.

\footnotetext{
8 Sin poder aquí detenernos en este tema, es importante indicar que nuestras evidencias también comprueban el fracaso de la sindicatura en la Argentina. Nuestros hallazgos dan cuenta de los fuertes vínculos entre síndicos y socios mayoritarios de las empresas, actuando los primeros como uno de los principales amalgamadores de las redes corporativas locales (más que como fiscalizadores), en un contexto donde la propiedad nacional y familiar perdió peso dentro de las grandes empresas al ser desplazadas por las multinacionales, tal como se indicó.
} 


\section{Conclusiones}

Esta investigación sobre las estructuras de redes de directorio en Argentina y Chile en el período 1969-1970 ha enfatizado en primer lugar cómo los cambios en la estructura de propiedad a partir de los años 30 (cuando se imponen las políticas ISI) impactaron en la configuración de las redes de directorio en cada país. En segundo lugar, este trabajo ha avanzado sobre un terreno poco explorado previamente en la literatura al analizar las redes de directorio en países con mercados financieros escasamente desarrollados y con una presencia poco significativa de empresas cotizantes en bolsa de valores. Además, ampliamos el foco de la literatura anterior sobre cómo los escenarios institucionales y los sistemas empresariales nacionales pueden afectar el modo en que las empresas más grandes -incluyendo las multinacionales- organizan sus redes corporativas para enfrentar las condiciones del entorno.

El análisis comparativo ha mostrado la importancia de dos factores: la denominada turbulencia del entorno $y$, las estructuras de propiedad dominantes en este momento En relación al primer aspecto, nuestros resultados sugieren que la turbulencia económica y política que caracterizó a la Argentina durante el período analizado socavó el capital social que proporcionan las redes en escenarios más estables. Los resultados que se informan aquí sostienen la idea de que un entorno turbulento puede dificultar el acceso al conocimiento y su transferencia y disminuir la receptividad del directorio (Shropshire, 2010). En esta línea, otro hallazgo del presente trabajo es que la violencia contra los empresarios y una comunidad empresarial fragmentada pueden reducir las motivaciones de los empresarios para ser miembros de varios directorios. Como consecuencia, el grado y la densidad promedio de las redes (interpretado como un indicador de la masa de capital social) era más alto en Chile, y por lo tanto, lo eran también el control y la integración social de la elite empresarial (Windolf, 2008). En efecto, el presente trabajo parece confirmar la teoría que sugiere que los beneficios de los vínculos sociales dependen del contexto (Burt, 1997; Gulati y Higgins, 2003). Las empresas argentinas, inmersas en un entorno económico y político más hostil, se apoyaron menos en los vínculos de los directorios que sus pares en Chile. En consecuencia, las redes de directorio en Argentina estaban más dispersas y fragmentadas que las chilenas.

Tal como fue planteado previamente, un segundo y crucial factor que explica las diferencias en las estructuras de las redes de directorio fueron las estructuras de propiedad (Rinaldi y Vasta, 2005; Khana y Rivkin, 2006). La escasa presencia de empresas de grupos económicos entre las empresas más grandes de Argentina y el rol de los bancos de propiedad estatal como principales proveedores de crédito 
industrial pueden haber reducido las redes de directorios entre las empresas. A diferencia de esto, encontramos que las empresas chilenas se apoyaron más en las redes de directorios como herramientas de coordinación y control. Hemos propuesto que los grupos económicos chilenos utilizaban las redes de directorios como un mecanismo de control específico. Por ejemplo, los gerentes y propietarios de grupos que pertenecían a directorios de bancos controlaban el flujo de recursos financieros. Los grupos económicos chilenos también se apoyaban en las RD para controlar las empresas afiliadas al grupo y para integrarlas con otras organizaciones. En parte, esto es compatible con investigaciones realizadas en años subsiguientes, que muestran que los controladores de egrupos económicos chilenos confían en un número relativamente reducido de personas para administrar los negocios, y estos individuos se involucran exclusivamente como miembros de directorios de empresas afiliadas a sus grupos (Lefort y Walker, 2000b; Majluf, Abarca, Rodriguez y Fuentes, 1998; Silva, Majluf y Paredes, 2006). Las redes de directores son particularmente notables para los actores corporativos en Chile, porque construyen los límites de los grupos económicos (Khanna y Rivkin, 2006).

También hemos demostrado las diferencias entre Argentina y Chile con respecto a la distribución del capital social entre las empresas. Las empresas en industrias que el gobierno argentino consideraba estratégicas estaban en el núcleo de la red, y por lo tanto tuvieron más capital social a nivel del directorio (Haynes y Hillman, 2010). En efecto, el ranking de las diez empresas más centrales incluía a varias multinacionales y a empresas locales vinculadas a sectores estratégicos tales como Acindar, Loma Negra, Dalmine, Pasa, Siemens, Duperial, Celulosa y Esso. Por el contrario, en Chile, los bancos fueron actores importantes en las redes corporativas así como las empresas cuyos propietarios eran grupos económicos locales.

Por último, los resultados que aquí se detallan parecen indicar que una densa red empresaria en Chile desencadenaría un mayor interés en fortalecer las alianzas entre empresas, siendo las redes de directorio un instrumento de control que facilitó la cooperación dentro de la comunidad empresarial (Windolf, 2008). Nuestra investigación también sugiere que, aunque las redes de directorio argentinas habrían sido menos relevantes como medios para diseminar prácticas empresariales y para reducir la incertidumbre y construir confianza entre las empresas. Esto confirma la pluralidad de modalidades con las cuales se ha manifestado históricamente el fenómeno del entrecruzamiento de directorios en el sistema capitalista 


\section{Limitaciones de la investigación}

Los resultados del presente trabajo están sujetos a limitaciones inherentes a la disponibilidad de datos. En primer lugar, los resultados se restringen a las empresas más grandes de Chile y Argentina. Investigaciones futuras podrían examinar las estrategias de redes de directorios en empresas estatales y en otras empresas de tamaño mediano controladas por grupos económicos que no figuraban en la lista de las empresas más grandes de Argentina y Chile en 1970. La presente investigación plantea otras preguntas que no pueden responderse a partir de los datos actuales. Por ejemplo, los trabajos futuros podrían explorar la funcionalidad de las redes de directorios en los dos países y proporcionar evidencia más directa de las consecuencias que las redes de directorio tuvieron en el funcionamiento de las empresas grandes y en el comportamiento de las elites empresariales al final del período del modelo ISI (ya que ambos países adoptaron reformas de mercado desde mediados de la década del 70, si bien con diferente cronología y resultados). En particular, una larga tradición de investigación se ha focalizado en el rol de las elites de negocios y ha encontrado que las redes de elite son excluyentes (Tokman, 1973). Sin embargo, investigaciones recientes han sugerido que una mayor cohesión social entre los miembros de una comunidad generaría más prosperidad (Marquis 2003). Trabajos futuros podrían explorar los efectos de las elites empresariales cohesivas en Latinoamérica y su rol en el desarrollo económico del país. Por ultimo, un trabajo longitudinal permitiría establecer si las diferencias halladas entre Argentina y Chile se repiten a lo largo del tiempo o si se asociaban al período específico analizado en este trabajo. 


\section{Bibliografía}

AAVV. (1972). El libro de las 91: las empresas monopólicas y el área social de la economía chilena, Santiago, Ed. Barco de Papel.

Acuña, C., Galiani, S. \& Tommasi, M. (2006). Understanding the Political Economy of Structural Reform: The case of Argentina. Documento de Trabajo, 91, Departamentos de Economía y de Humanidades, Universidad de San Andrés.

Ardanaz, M., Scartascini, C. \& Tommasi, M., (2010). Political Institutions, Policymaking, and Economic Policy in Latin America. Working Paper Series No. 158, Inter-American Development Bank.

Azpiazu, D. \& Kosacoff, B. (1985). Las empresas transnacionales en la Argentina, Documento de Trabajo, 16, Buenos Aires: CEPAL.

Barbero, M.I. \& Rocchi, F. (2003). Industry and Industrialization in Argentina in the Long Run: from its Origins to the 1970's. , en della Paolera, G. \& Taylor, A. (eds.), A New Economic History of Argentina, Cambridge, Cambridge University Press.

Bearden, J. \& Mintz, B. (1992). The Structure of Class Cohesion: The Corporate Network and its Dual, en Mizruchi, M., Schwartz, M. \& Granovetter, M., Intercorporate Relations: The Structural Analysis of Business (Structural Analysis in the Social Sciences), Nueva York, Cambridge University Press.

Behrens Fuchs, R. (1985). Los bancos e instituciones financieras en la historia económica de Chile. 1811-1983. Tesis doctoral, Pontificia Universidad Católica de Chile.

Bonacich, P. (1987). Power and Centrality: A Family of Measures. The American Journal of Sociology, 92 (5): 1170-1182.

Borgatti, S., Everett, M. \& Freemen, L. (2002). Ucinet for Windows: Software for Social Network Analysis. Harvard, MA: Analytic Technologies.

Boyd, B. (1990). Corporate linkages and organizational environment: A test of the resource dependence model. Strategic Management Journal, 11: 419-430.

Bozzoli, G., della Paolera, G. \& Irigoin, M. (2003). Passing the Buck: Monetary and Fiscal Policies in Argentina: 1852-2000, in della Paolera, G and Taylor, A (eds), A New Economic History of Argentina, Cambridge: Cambridge University Press.

Brennan, J. (2007). Prolegomenon to Neoliberalism: The Political Economy of Populist Argentina. Latin American Perspectives, 34: 49-66.

Bucheli, M. \& Salvaj, E. (2009), Embrace Your Enemy, Harvard Business Review, Mayo, 22-23. 
Bucheli, M. \& Salvaj, E. (2011). "Corporate Boards and Political Strategies of Multinational Corporations, Business Groups, and State-Owned Enterprises: The Telecommunications Sector in Chile, 1958-2005". Working paper.

Bucheli, M. \& Salvaj, E. (2012). "Multinational Corporations' Obsolescing Political Legitimacy: ITT in Chile, 1920-1972." Business History Review (Forthcoming)

Burris, V. (2005). Interlocking Directorates and Political Cohesion among Corporate Elites. American Journal of Sociology, 111 (1): 249-283.

Burt, R. (1997). The contingent value of social capital. Administrative Science Quarterly, 42: 339-365.

Carpenter, M. A., \& Westphal, J. D. (2001). The strategic context of external network ties: Examining the impact of director appointments on board involvement in strategic decision. Academy of Management Journal, 4 (4), 639-660.

Corrado, R. \& Zollo, M. (2006). Small worlds evolving: governance reforms, privatizations, and ownership networks in Italy. Industrial and Corporate Change 15(2): 319-352.

Couyoumdjian, R., Millar, R. \& Tocornal, J. (1993), Historia de la Bolsa de Comercio de Santiago, 1893-1993. Un siglo del mercado de valores en Chile. Santiago: Bolsa de Comercio de Santiago.

Davis, G. \& Mizruchi, M. (1999). The money center cannot hold: commercial banks in the U.S. system of corporate governance. Administrative Science Quarterly 44: 215-239.

Davis, G. \& Robbins, G. (2004). Nothing but Net? Networks and Status in Corporate Governance. In Knorr Cetina, K. and Preda, A. (eds) The Sociology of Financial Markets. Oxford, Oxford University Press: 290-311.

Davis, G. Yoo, M., \& Baker, W. (2003). The small world of the American corporate elite, 1982-2001. Strategic Organization, 1(3): 301-326.

Fourcade-Gourinchas, M. \& Babb, S. (2002). The rebirth of the liberal creed: paths to neoliberalism in four countries. American Journal of Sociology 108(3): 533-579.

Gillespie, R. (1982). Soldiers of Peron: Argentina's Montoneros. Oxford: Clarendon Press.

Granovetter, M. (1993). The nature of economic relationship, in Swedberg R. (ed.), Explorations in Economic Sociology. New York, Russell Sage Foundation.

Guía de Sociedades Anónimas, (1972). Buenos Aires: Cámara Argentina de Sociedades Anónimas. . 
Guillén, M. (2000). Business groups in emerging economies: a resource-based view. Academy of Management Journal, 43(3): 362-380.

Gulati, R. \& Higgins, M. (2003). Which ties matter when? The Contingent effects of interorganizational partnerships on IPO success. Strategic Management Journal, 24: 127-144.

Hambrick, D; Werder, A \& Zajac, E. (2008). New Directions in Corporate Governance Research. Organization Science, 19 (3): 381-385.

Haynes, K. \& Hillman, A. (2010). The effect of board capital and CEO power on strategic change. Strategic Management Journal 31: 1145-1163.

Hollander, M. \& Wolfe, D. A. (1999). Nonparametric Statistical Methods (2nd Ed.). Canada; Wiley.

Holmes J. (2001). Political Violence and Regime Change in Argentina: 1965-1976. Terrorism and Political Violence, 13, (1): 134-154.

Islas, G. (2010). Gobierno corporativo y estructura de propiedad en Chile: 18542005, en El impacto histórico de la Globalización en Argentina y Chile, Buenos Aires: Editorial Temas.

Kang, E. (2008). Director interlocks and spillover effects of reputational penalties from financial reporting fraud. Academy of Management Journal 51 (3): 537-555.

Khanna, T. \& Rivkin, J. (2006). Interorganizational ties and business group boundaries: evidence from an emerging economy. Organization Science 17(3): 333-352.

Khavisse, M. \& Piotrkowski, J. (1973), La consolidación hegemónica de los factores extranacionales. El caso de las cien empresas industriales más grandes, Buenos Aires: Sec. de Planeamiento y Acción de Gobierno.

Kline, J. (1992). Foreign Investment Strategies in Restructuring Economies. Learning from Corporate Experiences in Chile, Westport: Greenwood Publishing Group, Inc.

Koenig, T.; Gogel, R. \& Sonquist, J. (1979), Models of the Significance of Interlocking Corporate Directorates American. Journal of Economics and Sociology. 38 (2) 173-186.

Lefort, F. \& Walker, E. (2000a). The Effects of Economic and Political Shocks on Corporate Governance Systems in Chile. Abante 2(2): 183-206.

Lefort, F. \& Walker, E. (2000b). Ownership and Capital Structure of Chilean Conglomerates: Facts and Hypotheses for Governance. Abante 3(1): 3-27. 
Lefort, F. (2010). Business Groups in Chile, en Colpan, A., Hikino, T. \& Lincoln, J. (eds.), The Oxford Handbook of Business Groups, Oxford: Oxford University Press.

Lester, R. Hillman, A. Zarkhoohi, A. \& Cannella, A. (2008). A former government officials as outside directors: the role of human and social capital. Academy of Management Journal 51 (5): 999-1013.

Lluch, Salvaj \& Barbero (2011). Redes Corporativas y Grupos Económicos en Argentina (a fines de la etapa de Sustitución de importaciones). Working paper.

Majluf, N., Abarca, N., Rodriguez, \& Fuentes, (1998). Governance and Ownership Structure in Chilean Economic Groups. Abante 1(1): 111-139.

Mallon, R. \& Sourrouille, J. (1975). Economic policy-making in a conflict society: The Argentine case. Cambridge: Harvard University Press.

Marquis, C. (2003). The Pressure of the Past: Network Imprinting in Intercorporate Communities. Administrative Science Quarterly, 48 (4): 655-689.

Mizruchi, M. (1996). What do interlocks do? An Analysis, Critique, and Assessment of Research on Interlocking Directorates. Annual Review of Sociology 22: 271-98.

Pfeffer, J., \& Salancik, G. R. (1978). The external control of organizations: A resource dependence perspective. New York: Harper \& Row.

Podolny, J. M. (2001). Networks as the pipes and prisms of the market. American Journal of Sociology, 107: 33-60.

Revista Competencia Económica (1970), Buenos Aires, Argentina, (43).

Rhee, M. \& Valdez, M. (2009). Contextual factors surrounding reputation damage with potential implications for reputation repair. Academy of Management Review, 34(1):146-168.

Rinaldi, A. \& Vasta, M. (2005). The Structure of Italian Capitalism, 1952-1972: New Evidence Using the Interlocking Directorates Technique. Financial History Review, 2: $173-198$.

Romero, L.A. (2009). La violencia en la historia argentina reciente: un estado de la cuestión, en Anne Pérotin-Dumon (dir.). Historizar el pasado vivo en América Latina (on-line).

Ross Schneider, B. (2004). Business Politics and the State in 20th Century Latin America. New York: Cambridge University Press.

Rougier, M. (2004). Industria, finanzas e instituciones en la Argentina. La experiencia del Banco Nacional de Desarrollo. 1967-1976. Bernal: Universidad Nacional de Quilmes. 
Salvaj, E. \& Ferraro, F. (2005), Las Redes de Propiedad y de Consejos de Administración del IBEX 35. en Los accionistas y el gobierno de la empresa. Análisis de la situación española. Edited by Joan Enric Ricart, Jose Luis Alvarez and Julia Gifra. Ediciones Deusto: 179-211, 179-211.

Sapelli, C. (2003), The political economics of Import substitution Industrialization, Economics Institute Working Paper No. 257, Santiago de Chile: PUC.

Scott, J. (2007). Social Network Analysis, a handbook. Second Edition. London, UK: Sage Publications.

Shropshire, C. (2010). The Role of the Interlocking Director and Board Receptivity in the Diffusion of Practices. Academy of Management Review, 35 (2): 246-264.

Silva, F., Majluf, N. \& Paredes, R. (2006). Family ties, interlocking directors and performance of business groups in emerging countries: The case of Chile. Journal of Business Research 59: 315-321.

Skidmore, T. \& Smith, P. (2001). Modern Latin America. New York: Oxford University Press.

Solimano, A. (2002). Political violence and economic development in Latin America: issues and evidence, Serie macroeconómica del desarrollo, Santiago de Chile: CEPAL.

Sourrouille, J. (1976). The Impact of Transnational Enterprises on Employment and Income: The Case of Argentina, World Employment Program Research, Working Papers, Geneva: International Labor Office.

Sourrouille, J., Kosacoff, B. \& Lucangeli, J. (1985). Transnacionalización y política económica en la Argentina, Buenos Aires: CEAL/CEPAL.

Stokman, F., Ziegler, R. \& Scott, J. (1985). Networks of Corporate Power: A Comparative Analysis of Ten Countries. Cambridge: Polity Press.

Tokman, V. (1973). Concentration of economic power in Argentina. World Development 1 (10): 33-41.

Universidad Argentina de la Empresa \& Instituto de Investigaciones Bancarias y Monetarias (1973). Bancar Nro. 2, Buenos Aires: UAE

Useem, M. (1984), The inner circle. New York, Oxford University Press.

Wasserman, S. \& Faust, K. (1994). Social Network Analysis. Methods and applications. Cambridge. UK: Cambridge University Press.

Windolf, P. (2002). Corporate Networks in Europe and the United States, Oxford: Oxford University Press. 
Windolf, P. (2008). Coordination and control in corporate networks: United States and Germany in comparison, 1896-1938. European Sociological Review, 25(4): 443-457.

Zeitlin, M. \& Ratcliff, R. (1988). Landlords \& Capitalists: The Dominant Class of Chile. Princeton: Princeton University Press. 


\section{Apéndice}

\begin{tabular}{|l|c|c|c|c|c|c|c|c|c|c|}
\hline \multirow{3}{*}{ Año } & \multicolumn{3}{|c|}{ Autoridad Legal } & \multicolumn{5}{c|}{ Sector } & \multicolumn{3}{c|}{ País de Origen } \\
\cline { 2 - 14 } & $\begin{array}{c}\text { Ley } \\
14222\end{array}$ & $\begin{array}{c}\text { Circulares } \\
2324 / 3831\end{array}$ & $\begin{array}{c}\text { Ley } \\
14780\end{array}$ & $\begin{array}{l}\text { Equipamiento } \\
\text { Transporte }\end{array}$ & $\begin{array}{l}\text { Prod. } \\
\text { Quím }\end{array}$ & $\begin{array}{l}\text { Maquinar } \\
\text { ia }\end{array}$ & Otros & EEUU & Alemania & Otros \\
\hline 1958 & - & 4.9 & 12.9 & 1.2 & 4.2 & 5.1 & 2.4 & 6.4 & 0.4 & 6.1 \\
\hline 1959 & - & - & 209.3 & 63.1 & 85.4 & 6.7 & 54.0 & 106.5 & 14.2 & 78.5 \\
\hline 1960 & - & - & 111.7 & 18.0 & 63.6 & 6.9 & 23.2 & 71.3 & 11.7 & 28.7 \\
\hline 1961 & - & - & 133.3 & 51.7 & 32.0 & 2.1 & 47.6 & 74.5 & 1.5 & 57.3 \\
\hline 1962 & - & - & 85.7 & 1.6 & 11.6 & 5.4 & 67.2 & 70.1 & 2.7 & 12.9 \\
\hline 1963 & - & - & 34.6 & 14.4 & 1.3 & 7.2 & 11.7 & 15.7 & 1.0 & 17.9 \\
\hline 1964 & - & - & 33.8 & 20.7 & 1.1 & 6.6 & 5.4 & 0.5 & 1.9 & 21.3 \\
\hline 1965 & - & - & 6.3 & 0.3 & 0.4 & 2.4 & 3.3 & 2.0 & 0.7 & 2.6 \\
\hline 1966 & - & - & 2.5 & 0.3 & 0.2 & 0.3 & 1.7 & 0.8 & 0.4 & 1.3 \\
\hline 1967 & - & - & 13.1 & 9.2 & 0.7 & 0.1 & 3.0 & 9.9 & 0.8 & 2.9 \\
\hline 1968 & - & - & 31.5 & 13.1 & 6.6 & 3.7 & 8.1 & 20.9 & 2.0 & 8.6 \\
\hline 1969 & - & - & 59.1 & 5.2 & 46.2 & 2.7 & 5.0 & 12.0 & 0.8 & 46.3 \\
\hline 1970 & - & - & 9.8 & - & 0.1 & - & 9.6 & 0.2 & 1.6 & 8.0 \\
\hline
\end{tabular}

Tabla A1: Autorizaciones de inversiones de capital extranjero (en millones de dólares). Fuente: Ministerio de Economía, Informe económico, y Decretos del Poder Ejecutivo Nacional citados en Sourrouille, Juan (1976).

\begin{tabular}{|l|l|}
\hline \multicolumn{1}{|c|}{ Empresa } & Intereses Propietarios Controlantes \\
\hline Co. De Aceros Pacífico(CAP) & Corfo \\
\hline Fabricantes de Papel y Cartón & Familia Matte y asociados \\
\hline Empresas Industriales "El Melon" & Familia Cortés y asociados \\
\hline Co Sudamericana de Vapor (CSAV) & Familias Vial y MacAuliffe y asociados \\
\hline Productos Sumar & Familia Sumar \\
\hline Cervecerías Unidas Co. & Familia Edwards y asociados \\
\hline Co. Electricidad industrias generales & Familia Claro y asociados \\
\hline Compañía Petrolera de Chile (COPEC) & No hay datos \\
\hline Ganadería Tierra del Fuego & Familia Braun-Menendez y asociados \\
\hline Carbon Lota-Schwager & Familias Cousiño,Claude y Cortés \\
\hline Empresa Minera Mantos Blancos & Mauricio Hochschild y asociados \\
\hline Productos de Algodón Chilenos Yarur & Familia Yarur Banna \\
\hline Algodón Hirmas & Familia Hirmas \\
\hline Co. Industrial (INDUS) & Familia Edwards y asociados \\
\hline Productos de cobre (MADECO) & Familia Simonetti y asociados \\
\hline Refinería de azúcar Viña del Mar (CRAV) & Familias Edwards, Claude y asociados \\
\hline Fabricación de Metal (MADEMSA) & Familia Simonetti y asociados \\
\hline Empresa Consumidores de Gas (GASCO) & Claudio Troncoso y asociados \\
\hline Empresas Periodísticas El Mercurio & Familia Edwards \\
\hline Asociación Renta Urbana "Pasaje Matte" & Familia Matte y asociados \\
\hline Textiles Caupolican & Yarur Banna y Grace \\
\hline Cristalería de Chile & $\begin{array}{l}\text { Control conjunto Corning PPG con Cousiño } \\
\text { y Edwards }\end{array}$ \\
\hline Compañía Distribución Nacional (CODINA) & Familia Schmutzer con familias Edwards y \\
& Claude \\
\hline Fábrica Nacional de Loza Penco \\
(FANALOZA) & Familia Díaz y asociados \\
\hline Fábrica de Esmaltes (FENSA) & Familia Briones y asociados \\
\hline & \\
\hline
\end{tabular}




\begin{tabular}{|l|l|}
\hline Empresa editorial Zig-Zag & Familia Helfmann y asociados \\
\hline Ind.Rayon Said y Químicos (RAYONSAID) & Familia Said \\
\hline Fábrica de vestimenta Bella Vista - Tomé & Intereses Yarur Asfura y Grace \\
\hline Telas Nacionales Tomé & Familia Furman y asociados \\
\hline Corp Navegación Petróleo. & Familias Braun-Menéndez yVial \\
\hline $\begin{array}{l}\text { Compañía Navegación Interoceánica de } \\
\text { Chile }\end{array}$ & Familia Braun-Menéndez \\
\hline Textiles Progreso & Familia Yarur Kazakia \\
\hline Saavedra Benard & Banco de Chile \\
\hline Impresiones y Litografía Universo & Familia Helfmann y asociados \\
\hline Compañía Minera Oruro & Mauricio Hochschild y asociados \\
\hline Compañía Minera Tamaya & Corfo e intereses privados \\
\hline Transportes Marítimos Coronel & Familias Cousiño y Claude \\
\hline
\end{tabular}

Tabla A2: Control de las 37 Mejores Empresas No Financieras en Chile, 1964-1966. Fuente: Zeitlin y Ratcliff, 1988.

\section{Datos}

Utilizamos una muestra de las empresas argentinas y chilenas más grandes a fines de la década de 1960. Las empresas más grandes de Chile se identificaron utilizando diversos criterios ya que Chile Economic News, publicada por CORFO, no divulgó la lista de las empresas chilenas más grandes durante 1967-1973. En primer lugar, utilizamos el libro de las 91 (AAVV, 1972), que nos permitió identificar a las 91 empresas monopólicas que funcionaban en Chile al comienzo de la década de 1970. Recogimos información de 63 de esas empresas; en dicha lista también identificamos 65 de las 100 empresas más grandes de acuerdo con el valor anual comercializado en 1969, según la Bolsa de Valores de Santiago. Incluimos 10 de las empresas de propiedad estatal más grandes y los 25 bancos más grandes en 1969, según Behrens Fuchs (1985). Nuestra base de datos final de Chile, incluyó a 165 empresas grandes de Chile. La información sobre la composición de sus directorios proviene de la Superintendencia de Bancos e Instituciones Financieras, de la Superintendencia de Valores y Seguros y de las memorias anuales de las empresas. En Argentina, recolectamos información de 83 grandes empresas según ventas, de acuerdo con el ranking de Revista Competencia Económica (1970). Obtuvimos información sobre la composición de los directorios de las empresas argentinas en 1971 de la Guía de Sociedades Anónimas (1972). Del ranking proporcionado por Bancar (1973), recogimos información de 33 de los 50 bancos más grandes de Argentina al comienzo de la década de 1970, incluyendo al síndico. La tabla A3 muestra el número de empresas por industria y tipo de propiedad. 


\begin{tabular}{|c|c|c|c|c|c|c|c|c|c|c|c|c|c|c|c|c|}
\hline & \multicolumn{16}{|c|}{ Propiedad } \\
\hline & \multicolumn{2}{|c|}{$\begin{array}{l}\text { Familias } \\
\text { Locales }\end{array}$} & \multicolumn{2}{|c|}{ Estatales } & \multicolumn{2}{|c|}{ Local Otros } & \multicolumn{2}{|c|}{ EMN } & \multicolumn{2}{|c|}{$\begin{array}{c}\text { Familias } \\
\text { locales-EMN }\end{array}$} & \multicolumn{2}{|c|}{$\begin{array}{c}\text { Local Otros } \\
\text { EMN }\end{array}$} & \multicolumn{2}{|c|}{$\begin{array}{c}\text { Estatal- } \\
\text { Local Otros }\end{array}$} & \multicolumn{2}{|c|}{ Total } \\
\hline & $\begin{array}{c}\text { Argen } \\
\text { tina }\end{array}$ & Chile & $\begin{array}{c}\text { Argen } \\
\text { tina }\end{array}$ & Chile & $\begin{array}{c}\text { Argen } \\
\text { tina }\end{array}$ & Chile & $\begin{array}{c}\text { Argen } \\
\text { tina }\end{array}$ & Chile & $\begin{array}{c}\text { Argen } \\
\text { tina }\end{array}$ & Chile & $\begin{array}{c}\text { Argen } \\
\text { tina }\end{array}$ & Chile & $\begin{array}{c}\text { Argen } \\
\text { tina }\end{array}$ & Chile & $\begin{array}{c}\text { Argen } \\
\text { tina }\end{array}$ & Chile \\
\hline Manufactura & 22 & 38 & 2 & 7 & 5 & 17 & 41 & 11 & 4 & 2 & 1 & 0 & 2 & 1 & 77 & 76 \\
\hline $\begin{array}{c}\text { Serv. } \\
\text { Financieros }\end{array}$ & 9 & 14 & 4 & 3 & 9 & 5 & 6 & 2 & 0 & 0 & 0 & 0 & 5 & 0 & 33 & 25 \\
\hline Seguros & 0 & 7 & 0 & 0 & 0 & 5 & 0 & 2 & 0 & 0 & 0 & 0 & 0 & 0 & 0 & 14 \\
\hline $\begin{array}{l}\text { Servicios } \\
\text { públicos }\end{array}$ & 0 & 1 & 1 & 2 & 0 & 3 & 0 & 3 & 0 & 0 & 0 & 0 & 0 & 1 & 1 & 10 \\
\hline Minería & 0 & 1 & 0 & 1 & 0 & 3 & 1 & 2 & 0 & 0 & 0 & 0 & 0 & 0 & 1 & 7 \\
\hline Transporte & 0 & 4 & 1 & 0 & 0 & 1 & 0 & 0 & 0 & 0 & 0 & 0 & 0 & 0 & 1 & 5 \\
\hline Act. Primarias & 0 & 7 & 0 & 0 & 0 & 1 & 1 & 2 & 0 & 0 & 0 & 0 & 0 & 0 & 1 & 10 \\
\hline Servicios & 1 & 5 & 0 & 0 & 0 & 0 & 6 & 1 & 4 & 0 & 0 & 0 & 0 & 0 & 2 & 15 \\
\hline Holdings & 0 & 3 & 0 & 0 & 0 & 0 & 0 & 0 & 0 & 0 & 0 & 0 & 0 & 0 & 0 & 3 \\
\hline Total & 32 & 80 & 8 & 13 & 14 & 41 & 50 & 27 & 4 & 2 & 1 & 0 & 7 & 2 & 116 & 165 \\
\hline
\end{tabular}

Tabla A3: Cantidad de empresas por tipo de propietario e industria.

\section{Método}

Utilizamos el análisis de redes sociales para probar nuestras hipótesis. Estudiamos las redes de directorios de las empresas más grandes de Chile y de Argentina con la ayuda del software UCINET (Borgatti, Everett, y Freeman, 2002). El primer paso en el análisis comparativo fue una revisión de las representaciones gráficas de las redes de ambos países. Utilizamos Netdraw (paquete de visualización de redes de UCINET).

En un segundo paso, calculamos y comparamos medidas estructurales de ambas redes (Ver Tabla 1 y su descripción). Como tercer paso, determinamos la identidad de los actores más centrales o de aquellos con un alto dominio y capital social en la red. Distintas medidas pueden capturar la centralidad de un directorio, incluyendo la centralidad de grado, la centralidad global (eigenvector) y la centralidad de intermediación (Scott, 2007; Wasserman y Faust, 1994). En este trabajo calculamos las tres centralidades (aunque sólo mostramos los resultados de la centralidad de intermediación debido a la alta correlación existente entre ellas). La centralidad de grado es el número de directorios a los cuales está conectado un cierto directorio; la centralidad global ofrece una variante de la centralidad de grado simple. Según esta medida, un nodo es más central si los nodos con los que se conecta son también centrales (Bonacich, 1987). Así, un directorio conectado a muchos directorios que están a su vez bien conectados obtiene un puntaje alto, pero un directorio conectado sólo a directorios aislados consigue un puntaje más bajo, aunque posea una centralidad de grado alta. La centralidad de 
intermediación sugiere que un directorio que media entre las relaciones de otros directorios puede controlar el flujo de comunicación y es por eso importante (Wasserman y Faust, 1994). De esta manera, esta medida da indicios de la medida en la cual un directorio facilita el flujo de información a través de la elite empresarial

Finalmente, aplicamos el test de Mann-Whitney para investigar si existían diferencias significativas entre las distintas medidas de centralidad de las instituciones financieras en contraposición a instituciones no financieras de un mismo país, las multinacionales en contraposición a empresas locales, y empresas de propiedad de grupos económicos o familias, en contraposición a aquellas que no pertenecen a grupos económicos. Aplicamos dicha prueba no-paramétrica porque la distribución de las medidas de centralidad era no-normal (Hollander y Wolfe, 1999).

\begin{tabular}{|c|c|c|c|c|c|c|c|}
\hline \multicolumn{4}{|c|}{ Argentina } & \multicolumn{4}{|c|}{ Chile } \\
\hline Director & $\begin{array}{l}\text { Interme } \\
\text { diación }\end{array}$ & Profesión & $\begin{array}{l}\text { Funcionario de } \\
\text { Gobierno }\end{array}$ & Director & \begin{tabular}{|l|} 
Intermed \\
iación
\end{tabular} & Profesión & $\begin{array}{l}\text { Funcionario de } \\
\text { Gobierno }\end{array}$ \\
\hline Diego Arguello & 0.067 & $\begin{array}{l}\text { Información no } \\
\text { disponible }\end{array}$ & $\begin{array}{l}\text { Información no } \\
\text { disponible }\end{array}$ & $\begin{array}{l}\text { Agustin } \\
\text { Edwards } \\
\text { Eastman }\end{array}$ & 0.031 & Empresario & No \\
\hline $\begin{array}{l}\text { Jorge Eduardo } \\
\text { O'Farrell }\end{array}$ & 0.075 & Abogado & no & $\begin{array}{l}\text { Salustio Prieto } \\
\text { Calvo }\end{array}$ & 0.032 & Empresario & No \\
\hline $\begin{array}{l}\text { Damián Beccar } \\
\text { Varela }\end{array}$ & 0.084 & Abogado & no & $\begin{array}{l}\text { Edgardo Cruz } \\
\text { Plaza }\end{array}$ & 0.033 & Ingeniero & $\begin{array}{l}\text { Superintendente de } \\
\text { Servicios Eléctricos }\end{array}$ \\
\hline \begin{tabular}{|l} 
Enrique \\
Steggman
\end{tabular} & 0.084 & Empresario & \begin{tabular}{|l|} 
Sub-secretario \\
Nacional de \\
Industria y Minería \\
(1962) Presidente \\
de Comercialización \\
Mineral (1962)
\end{tabular} & $\begin{array}{l}\text { Recaredo Ossa } \\
\text { Undurraga }\end{array}$ & 0.033 & Empresario & No \\
\hline José Negri & 0.089 & Ingeniero & No & $\begin{array}{l}\text { Jorge Ross } \\
\text { Ossa }\end{array}$ & 0.034 & $\begin{array}{l}\text { Ingeniero } \\
\text { Químico/ } \\
\text { Empresario }\end{array}$ & No \\
\hline \begin{tabular}{|l} 
Jorge Nicolas \\
Zaefferer Toro
\end{tabular} & 0.089 & Abogado & $\begin{array}{l}\text { Sub-secretario de } \\
\text { Económia del Estado } \\
(1959-1962) / \\
\text { Secretario de } \\
\text { Comercio } 1962\end{array}$ & \begin{tabular}{|l} 
Aurelio \\
Fernandez \\
Barros
\end{tabular} & 0.036 & Abogado & No \\
\hline Emilio Gagliardi & 0.095 & Ingeniero & $\begin{array}{l}\text { Información no } \\
\text { disponible }\end{array}$ & $\begin{array}{l}\text { Jorge Silva } \\
\text { Romo }\end{array}$ & 0.036 & Abogado & No \\
\hline Silvio Gagliardi & 0.095 & Ingeniero & $\begin{array}{l}\text { Director General de } \\
\text { Provisiones } \\
\text { Estatales, Director } \\
\text { de Inversiones } \\
\text { Mineras }\end{array}$ & $\begin{array}{l}\text { Anacleto } \\
\text { Angelini } \\
\text { Fabbri }\end{array}$ & 0.04 & Empresario & No \\
\hline Rodolfo Moltedo & 0.108 & Abogado & No & $\begin{array}{l}\text { Felix Huttner } \\
\text { Skall }\end{array}$ & 0.04 & $\begin{array}{l}\text { Información } \\
\text { no disponible }\end{array}$ & $\begin{array}{l}\text { Información no } \\
\text { disponible }\end{array}$ \\
\hline
\end{tabular}




\begin{tabular}{|c|c|c|c|c|c|c|c|}
\hline Alberto López & 0.126 & $\begin{array}{l}\text { Contador } \\
\text { Público }\end{array}$ & \begin{tabular}{|l|} 
Director General de \\
Impuestos al Crédito
\end{tabular} & $\begin{array}{l}\text { Jorge Raby } \\
\text { Birrel }\end{array}$ & 0.041 & Abogado & No \\
\hline $\begin{array}{l}\text { Carlos Alberto } \\
\text { Juni }\end{array}$ & 0.126 & Abogado & \begin{tabular}{|l|} 
Secretario de \\
Estado. Ex- ministro
\end{tabular} & $\begin{array}{l}\text { Ernesto Barros } \\
\text { Jarpa }\end{array}$ & 0.045 & Abogado & $\begin{array}{l}\text { Ministro de Relaciones } \\
\text { Exteriores } \\
1921 / 1926 / 1942\end{array}$ \\
\hline Carlos Dietl & 0.129 & Ingeniero & no & \begin{tabular}{|l} 
Manuel \\
Zanartu \\
Campino
\end{tabular} & 0.045 & $\begin{array}{l}\text { Ingeniero / } \\
\text { Empresario }\end{array}$ & No \\
\hline Andrea Wynveldt & 0.151 & $\begin{array}{l}\text { Contador } \\
\text { Público }\end{array}$ & no & $\begin{array}{l}\text { Vicente } \\
\text { Izquierdo } \\
\text { Besa }\end{array}$ & 0.048 & $\begin{array}{l}\text { Ingeniero / } \\
\text { Empresario }\end{array}$ & No \\
\hline $\begin{array}{l}\text { Eduardo Maria } \\
\text { Huergo }\end{array}$ & 0.156 & Ingeniero & $\begin{array}{l}\text { Ministro de Obras } \\
\text { públicas e Industria } \\
\text { de Intervención } \\
\text { Nacional de Córdoba }\end{array}$ & $\begin{array}{l}\text { Pablo Aldunate } \\
\text { Phillips }\end{array}$ & 0.069 & Abogado & $\begin{array}{l}\text { Representative of } \\
\text { State }(1957-1961)\end{array}$ \\
\hline Jorge Decarli & 0.17 & $\begin{array}{l}\text { Información no } \\
\text { disponible }\end{array}$ & $\begin{array}{l}\text { Información no } \\
\text { disponible }\end{array}$ & $\begin{array}{l}\text { Hector Braun } \\
\text { Guevara }\end{array}$ & 0.07 & Empresario & No \\
\hline $\begin{array}{l}\text { Juan Pedro } \\
\text { Thibaud }\end{array}$ & 0.214 & Ingeniero & \begin{tabular}{|l|} 
Sub-secretario de \\
Energía (1966) Sub- \\
secretario de Minería \\
y Petróleo (1967)
\end{tabular} & $\begin{array}{l}\text { Arturo Quiroz } \\
\text { Fitzsimmons }\end{array}$ & 0.084 & $\begin{array}{l}\text { Ingeniero / } \\
\text { Empresario }\end{array}$ & No \\
\hline Gastón Texier & 0.234 & Empresario & No & \begin{tabular}{|l|} 
Guillermo \\
Correa \\
Fuenzalida
\end{tabular} & 0.091 & Abogado & $\begin{array}{l}\text { Ministro (1937-1938); } \\
\text { Ministro de Justicia } \\
(1946-1947) ; \\
\text { Representante del } \\
\text { Estado (1930-1934) }\end{array}$ \\
\hline Alfredo Lisdero & 0.254 & $\begin{array}{l}\text { Contador } \\
\text { Público }\end{array}$ & $\begin{array}{l}\text { Consultor de YPF } \\
(1940-46) \text { y } \\
\text { Consultor de UIA } \\
(1940-52)\end{array}$ & $\begin{array}{l}\text { Walter } \\
\text { Hess }\end{array}$ & 0.11 & Empresario & $\begin{array}{l}\text { Embajador chileno en } \\
\text { EEUU durante la crisis } \\
\text { Cuba-EEUU }\end{array}$ \\
\hline Eduardo Johnson & 0.318 & $\begin{array}{l}\text { Contador } \\
\text { Público }\end{array}$ & No & $\begin{array}{l}\text { Patricio Garcia } \\
\text { Vela }\end{array}$ & 0.118 & Empresario & No \\
\hline Enrique Roberts & 0.441 & Empresario & No & $\begin{array}{l}\text { Eliodoro Matte } \\
\text { Ossa }\end{array}$ & 0.231 & Empresario & No \\
\hline
\end{tabular}

Tabla A4: Directores que intermedian y conectan la red 